\title{
Cobalt Metal ALD: Understanding the Mechanism and Role of Zink Alkyl Precursors as Reductants for Low Resistivity Co Thin Films
}

\author{
David Zanders, ${ }^{1,2} \mathrm{Ji}$ Liu, ${ }^{3}$ Jorit Obenlüneschloß, ${ }^{1}$ Claudia Bock, ${ }^{4}$ Detlef Rogalla, ${ }^{5}$ Lukas Mai, ${ }^{1}$ Michael \\ Nolan, ${ }^{3}$ Seán T. Barry, ${ }^{2}$ and Anjana Devi ${ }^{1 *}$ \\ ${ }^{1}$ Inorganic Materials Chemistry, Ruhr University Bochum, Universitätsstr. 150, Bochum, 44801 Germany \\ ${ }^{2}$ Department of Chemistry, Carleton University, 1125 Colonel By Drive, Ottawa, Ontario, K1S 5B6 Canada \\ ${ }^{3}$ Tyndall National Institute, University College Cork, Lee Maltings, Cork T12 R5CP, Ireland \\ ${ }^{4}$ Microsystems Technology, Ruhr University Bochum, Universitätsstr. 150, Bochum, 44801 Germany \\ ${ }^{5}$ RUBION, Ruhr University Bochum, Universitätsstr. 150, Bochum, 44801 Germany
}

Keywords: Cobalt, Atomic Layer Deposition (ALD), Film Growth Mechanism, Reactivity, DFT

\begin{abstract}
In this work, we report a new and promising approach towards the atomic layer deposition (ALD) of metallic Co thin films. Utilizing the simple and known $\mathrm{CoCl}_{2}$ (TMEDA) (TMEDA $=\mathrm{N}, \mathrm{N}, \mathrm{N}$ ',N'-tetramethylethylenediamine) precursor in combination with the intramolecularly stabilized $\mathrm{Zn}$ aminoalkyl compound $\mathrm{Zn}(\mathrm{DMP})_{2}$ (DMP = dimethylaminopropyl) as auxiliary reducing agent, a thermal ALD process is developed that enables the deposition of Zn free Co thin films. ALD studies demonstrate the saturation behavior of both precursors, linearity in dependency of the applied number of cycles as well as investigations of the temperature dependency of film growth in a regime of $140-215^{\circ} \mathrm{C}$. While the process optimization is carried out on Si with native oxide, additional growth studies are conducted on Au and Pt substrates. This study is complemented by initial reactivity and suitability tests of several potential $\mathrm{Zn}$ alkyl reducing agents. For the $\mathrm{CoCl}_{2}$ (TMEDA) - Zn(DMP) $)_{2}$ combination, these findings allow to propose a series of elemental reaction steps hypothetically leading to pure Co film formation in the ALD process whose feasibility are probed by a set of DFT calculations. The DFT results show that for reactions of the precursors in the gas phase and on Co(111) substrate surfaces, a pathway involving C-C coupling and diamine formation through reductive elimination of an intermediate Co(II) alkyl species is preferred. Co thin films with an average thickness of $10-25 \mathrm{~nm}$ obtained from the process are subjected to thorough analysis comprising AFM, SEM, RBS/NRA as well as depth profiling XPS. Resistivity measurements for $\sim 22 \mathrm{~nm}$ thick films grown on a defined $\mathrm{SiO}_{2}$ insulator layer yield highly promising values in a range of $15-20 \mu \Omega \mathrm{cm}$ without any after treatment.
\end{abstract}

\section{Introduction}

While academia and industry alike have shown ongoing interest in metallic cobalt (Co) thin films for several decades, research and development have significantly expanded and reached new levels in the past couple of years. ${ }^{1}$ This is a direct consequence of industrial efforts to implement metallic Co thin films in novel technologies due to their attractive electrical, mechanical, and physical properties,${ }^{1-3}$ as well as the inability of established thin film materials such as copper $(\mathrm{Cu})$ to overcome their inherent limitations. These include inferior resistance towards electromigration and higher tendency towards diffusion under temperature or current density mediated stress. ${ }^{4,5}$ The replacement of $\mathrm{Cu}$ with Co as conductive contacts or interconnects in integrated circuit (IC) devices serves as an illustrative example and is an ongoing process driven by large IC device manufacturers. ${ }^{1}$ Other applications for Co thin films include the fields of spintronics $^{6,7}$ and giant magnetoresistance. ${ }^{8-10}$

Among the Co thin film fabrication methods relevant for microelectronics device processing, chemical vapor deposition (CVD) based processes have acquired a predominant role at and beyond the $10 \mathrm{~nm}$ node. ${ }^{11}$ Conventional CVD processes for which a broad variety of metal-organic complexes, and chemistries have been investigated ${ }^{12-19}$ are however at a disadvantage when compared with atomic layer deposition (ALD) processes: Often ALD outperforms CVD in terms of sub nanometer thick- ness control, film conformality and uniformity over topographically, and demanding substrate geometries. ${ }^{20,21}$ These benefits are due to ALD capitalizing on alternating and temporally separated self-limiting surface reactions of more than one precursor with a substrate surface so that the desired thin film material is (ideally) grown monolayer by monolayer. ${ }^{22,23}$ Arguably, the choice of suitable precursors is of utmost importance as their specific reactivity towards substrate surfaces and co-reactants dictates the potential success of an ALD process.

Using highly reactive radical and ion species, plasma enhanced - (PE)ALD - promises to significantly lower the deposition temperatures while maintaining high film quality. ${ }^{24}$ However, a review of the recent process literature illustrates that this only partially applies in the case of Co as the predominantly employed $\mathrm{Co}^{(0)}$ cyclopentadienyl ${ }^{25-27}$ and carbonyl ${ }^{28-30}$ based precursors in reaction with $\mathrm{H}_{2}, \mathrm{NH}_{3}$ or $\mathrm{N}_{2} / \mathrm{H}_{2}$ plasma only yield highly pure layers at temperatures often exceeding $300^{\circ} \mathrm{C}$. In the deposition temperature regime of $100{ }^{\circ} \mathrm{C}-200{ }^{\circ} \mathrm{C}$, contaminant levels of carbon, nitrogen and oxygen were often reported to vary between 5 - 10 at. $\%$ each. In addition to that, the risk of anisotropic growth on geometrically demanding three-dimensional structures highlights another potential problem associated with PEALD despite recent advancements. ${ }^{31,32}$ Addressing this, intrinsically more reactive Co precursors have been developed that are suitable for classical, thermal ALD which rather 
enables isotropic film growth. Among them all-nitrogen coordinated $\mathrm{Co}(\mathrm{II})$ acetamidinates ${ }^{33,34}$ and diazadienyls ${ }^{11,35}$ were demonstrated to be viable candidates in combination with a variety of co-reactants ranging from $\mathrm{H}_{2}, \mathrm{NH}_{3},{ }^{t} \mathrm{BuNH}_{2}, \mathrm{Et}_{2} \mathrm{NH}$, $\mathrm{CH}_{2} \mathrm{O}_{2}$ (formic acid) to 1,4-bis(trimethylsilyl)-1,4-dihydropyrazine. The deposition chemistry for ALD of metallic Co thin films developed over the past 20 years is rich, ${ }^{1}$ so it was surprising that a particularly appealing type of chemistry has received less attention: i.e. the employment of alkylation agents as reductants in ALD. This interesting concept has been reported for $\mathrm{Cu}$ ALD processes with $\mathrm{Cu}(\mathrm{I})$ diketiminate precursors and diethyl zinc $\left(\mathrm{Zn}\left(\mathrm{Et}_{2}\right)\right)$ as co-reactant. ${ }^{36}$ Subsequently, a limited number of processes with varying $\mathrm{Cu}(\mathrm{I}) / \mathrm{Cu}$ (II) precursors and $\mathrm{Zn}(\mathrm{Et})_{2}$ were demonstrated, ${ }^{37-39}$ and complementary theoretical studies were reported on how the ligand transfer chemistry between the alkylation agent and the surface adsorbed $\mathrm{Cu}$ species ideally took place and which follow-up reactions (inter- and intra-molecular) could yield metallic $\mathrm{Cu} .^{40,41}$ Despite its appeal, $\mathrm{Zn}(\mathrm{Et})_{2}$ became a double-edged sword as its low-thermal stability induced parasitic, non-saturating film growth (above $120^{\circ} \mathrm{C}$ ) as well as significant incorporation of $\mathrm{Zn}$ (up to 10 at.\%) in deposited films. ${ }^{41-43}$ A recent study on ZnO PEALD suggested the onset of $\mathrm{Zn}(\mathrm{Et})_{2}$ decomposition affecting the film growth to even be as low as $60{ }^{\circ} \mathrm{C} .{ }^{43}$

To address this crucial drawback, we present for the first time the ALD of metallic, Zn-free Co thin films using, intramolecularly stabilized $\mathrm{Zn}$ precursor $\mathrm{Zn}(\mathrm{DMP})_{2}{ }^{44}(\mathrm{DMP}=\mathrm{N}, \mathrm{N}-3-(\mathrm{di}-$ methylamino)propyl) with the Co precursor $\mathrm{CoCl}_{2}$ (TMEDA) (TMEDA = N,N,N',N'-tetramethylethylenediamine) that has previously been used for ALD of intermetallic thin films. ${ }^{45,46}$ The precursor pair was chosen based on the precedence for the formation of thermally labile $\mathrm{Co}(\mathrm{DMP})_{2}$ species in solution, ${ }^{47} \mathrm{a}$ bulk reactivity study with the neat reagents, as well as matching thermal properties that facilitate their usage in an F-120 ALD reactor. As a first step, a reactivity screening of several potential precursor combinations (see Scheme 1) comprising the wellknown $\mathrm{Zn}(\mathrm{Et})_{2}{ }^{43}$ as well as its less known amine stabilized con-

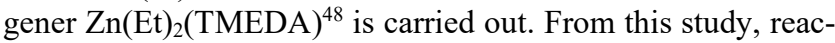
tion pathways are hypothesized for the surface chemistry of the $\mathrm{CoCl}_{2}$ (TMEDA) - $\mathrm{Zn}(\mathrm{DMP})_{2}$ process. These mechanistic considerations are examined through density functional theory (DFT) calculations that complement the experimental results. Calculations on the reaction enthalpies for the proposed steps rationalize the surface chemistry of Co deposition. This alternative chemistry route, with almost no initial delay in film growth, shows great potential to facilitate the direct growth of metallic Co films. To the best of our knowledge no similar study has been reported and we hope to motivate further research on the use of advanced $\mathrm{Zn}$ alkyls as co-reactants in metal ALD. We successfully demonstrate a thermal, self-saturating ALD process for Co deposition and the detailed analysis of the resulting Co thin films by complementary techniques such as AFM, SEM, RBS/NRA, XPS and resistivity measurements.

\section{Results and Discussion}

The choice of suitable precursor combinations is of crucial importance for an ALD process. For this study, $\mathrm{CoCl}_{2}$ (TMEDA) was chosen as the Co source, due to its successful usage and good performance in the ALD intermetallic thin films. This allowed us to focus on a limited number of potential $\mathrm{Zn}$ dialkyl co-reactants.
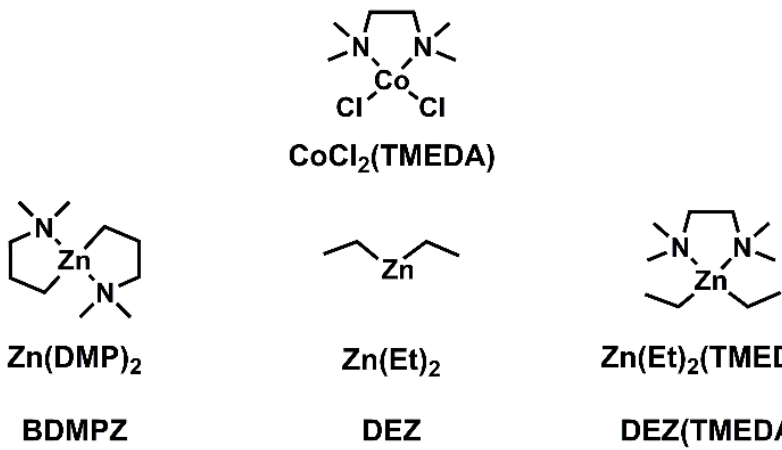

$\mathrm{Zn}(\mathrm{DMP})_{2}$

DEZ

$\mathrm{Zn}(\mathrm{Et})_{2}$ (TMEDA)

DEZ(TMEDA)

Scheme 1: Schematic structures of the Co precursor $\mathrm{CoCl}_{2}$ (TMEDA) and potential $\mathrm{Zn}$ dialkyl co-reactants namely $\mathrm{Zn}(\mathrm{DMP})_{2}, \mathrm{Zn}(\mathrm{Et})_{2}$ and $\mathrm{Zn}(\mathrm{Et})_{2}$ (TMEDA). Alternative denominations found in the literature are given for completion.

As the shortcomings of $\mathrm{Zn}(\mathrm{Et})_{2}$ as a reducing agent had already been demonstrated in the prior studies on $\mathrm{Cu}$ metal ALD, we were motivated to identify a viable, thermally robust, and generally less hazardous alternative. In this regard, we selected two compounds: a) non-pyrophoric TMEDA chelated $\mathrm{Zn}$ dialkyl $\mathrm{Zn}(\mathrm{Et})_{2}$ (TMEDA) which was used in CVD of fluorine doped $\mathrm{ZnO} ;{ }^{48}$ and b) $\mathrm{Zn}(\mathrm{DMP})_{2}$, an intramolecularly chelating $\mathrm{Zn}$ aminoalkyl with amino functionalization at the end of its alkyl chains. Latter was found to be a promising candidate due to its non-pyrophoric character and superior thermal stability in comparison to $\mathrm{Zn}(\mathrm{Et})_{2}$. It was developed in our group and used in PEALD of $\mathrm{ZnO}$ recently. ${ }^{44}$

\section{Reactivity Studies}

In order to evaluate the general capability of any of the $\mathrm{Zn}$ compounds to reduce $\mathrm{CoCl}_{2}$ (TMEDA) to Co under thermal stress, we decided to carry out and monitor a series of experiments where mixtures of the neat reagents were mixed and heated up in glass Schlenk flasks. The approach is exemplified for the combination $\mathrm{CoCl}_{2}$ (TMEDA) - $\mathrm{Zn}(\mathrm{DMP})_{2}$ (Figure 1). At first, $1 \mathrm{mmol}$ of each compound was added to the flask under inert gas and observed for any changes occurring at room temperature. In this case, darkening of the normally colorless $\mathrm{Zn}(\mathrm{DMP})_{2}$ was seen (Figure 1 a). No such changes were observed when $\mathrm{Zn}(\mathrm{Et})_{2}$ (TMEDA) was added to $\mathrm{CoCl}_{2}$ (TEMDA). In contrast, the stepwise and careful addition of $\mathrm{Zn}(\mathrm{Et})_{2}$ to $\mathrm{CoCl}_{2}$ (TMEDA) lead to fuming of the solid material decolorization to brown (c.f. Figure $\mathbf{S} \mathbf{1}$ in the supporting information (SI)). Subsequently, the crude mixtures were carefully heated up to $100{ }^{\circ} \mathrm{C}$ under static vacuum for one minute. In all cases except for

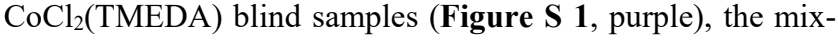
tures turned from dark brown to black melts (see Figure $\mathbf{1} \mathbf{b}$ and Figure S 1 green, yellow, red). Upon further heating to $200{ }^{\circ} \mathrm{C}$ under active roughing pump vacuum for a minute, all $\mathrm{Co}-\mathrm{Zn}$ compound mixtures formed partially metallic appearing residues at the bottom of the Schlenk flasks. Volatile by-products were either trapped in an attached receiver vessel or resublimed to lower temperature areas in the Schlenk flasks (see Figure 1 c). Images of these studies are compiled in Figure $\mathbf{S} \mathbf{1}$ in the SI. 


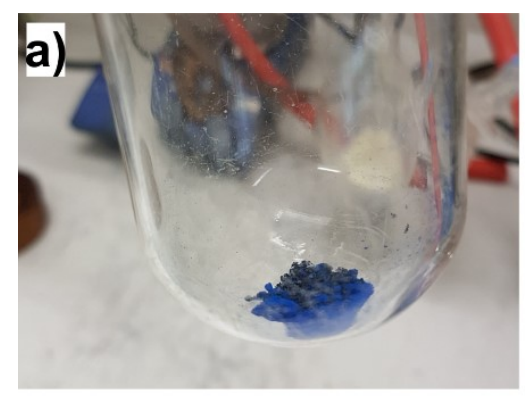

$\sim 25^{\circ} \mathrm{C}$ Under inertgas

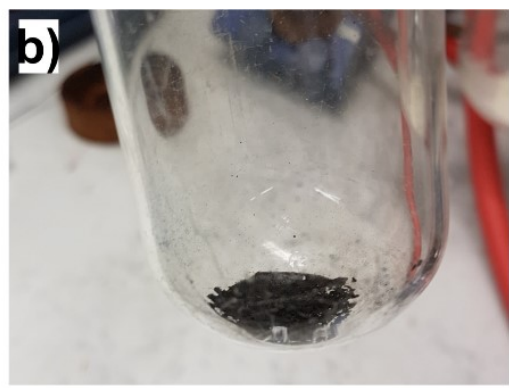

$\sim 100^{\circ} \mathrm{C}$ Static vacuum

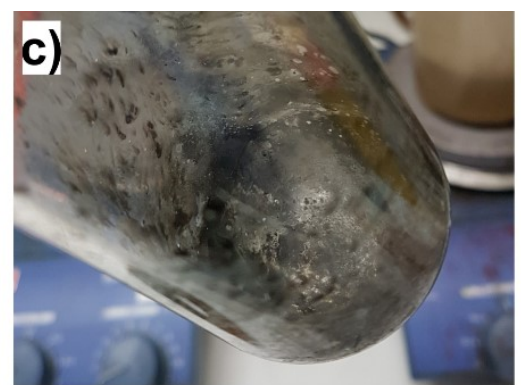

$\sim 200^{\circ} \mathrm{C}$

Active vacuum byproduct trapping
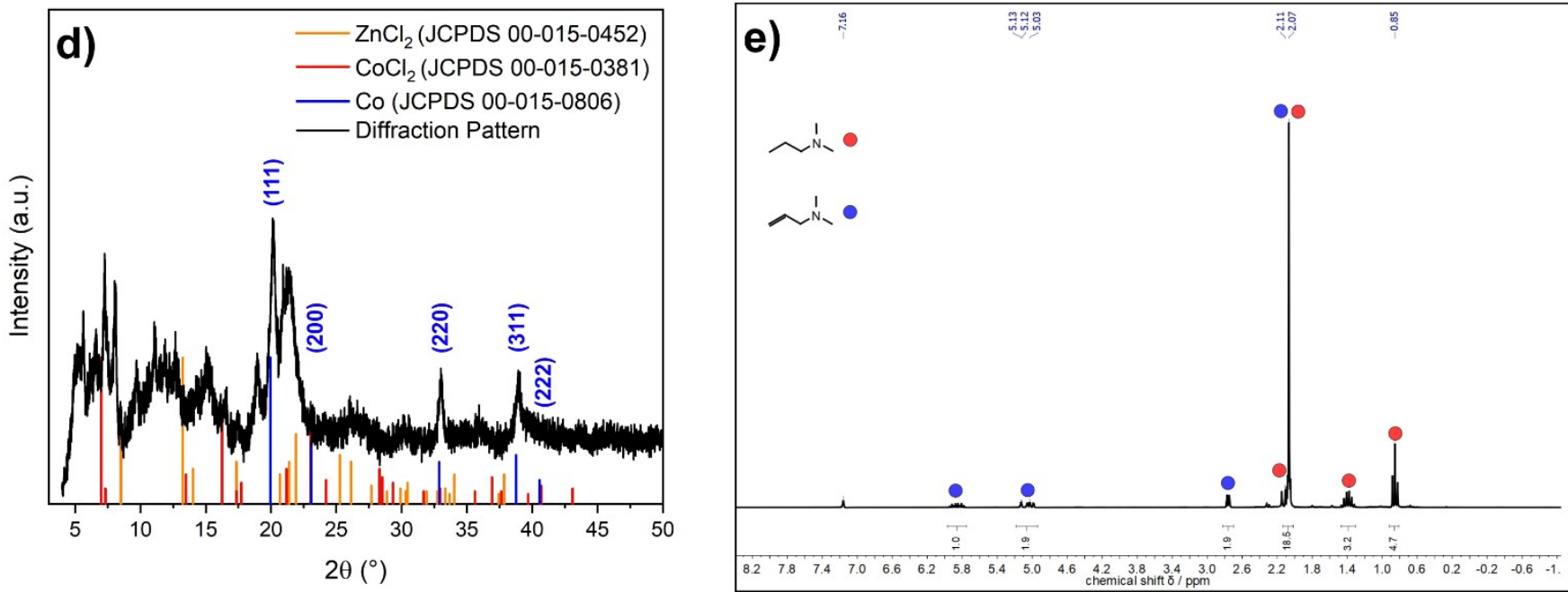

Figure 1: Exemplification of the multi aspect reactivity screening carried out for the precursor - co-reactant combination $\mathrm{CoCl}_{2}(\mathrm{TMEDA})-\mathrm{Zn}(\mathrm{DMP})_{2}$. a-c) Photographical illustration of the three-step heat-up procedure a) Colorless $\mathrm{Zn}(\mathrm{DMP})_{2}$ crystallites darkened significantly when in close contact with powdered $\mathrm{CoCl}_{2}$ (TMEDA) at room temperature. b) Heating to $100{ }^{\circ} \mathrm{C}$ yielded a dark melt, c) Formation of metal-like mirror at $200{ }^{\circ} \mathrm{C}$ under active vacuum. d) PXRD of the residual material demonstrating the presence of metallic Co. e) ${ }^{1} \mathrm{H}-\mathrm{NMR}$ analysis of volatile by-products, trapped during the second heat-up step, showing the formation of dimethylpropylamine (red marker) and dimethylprop-2-en-1-amine (blue marker).

In a next step, samples were drawn from the residues and subjected to powder X-ray diffraction (PXRD) analysis. As it can be seen for the combination $\mathrm{CoCl}_{2}$ (TMEDA) - $\mathrm{Zn}(\mathrm{DMP})_{2}$ (Figure $1 \mathbf{d})$, the presence of peaks assignable to cubic Co metal particles $^{49}$ in the residues was unambiguous despite the presence of other, less clearly identifiable peaks. For all residues, the predominant (111) reflection was observed. However, only for the combination $\mathrm{CoCl}_{2}$ (TMEDA) - $\mathrm{Zn}(\mathrm{DMP})_{2}$ less intense (220) and (311) reflections were monitored by PXRD as shown in Figure $1 \mathbf{d}$. All recorded PXR diffractograms are provided in Figure S 2. These observations demonstrated the general capability of all $\mathrm{Zn}$ co-reactants to induce reduction of the Co precursor upon thermal stress. The translation of this chemical reaction behavior into a controllable ALD process was a significant step in Co ALD process optimization described in a later section. From the analysis of trapped volatile by-products that were formed during the reaction of $\mathrm{CoCl}_{2}$ (TMEDA) and $\mathrm{Zn}(\mathrm{DMP})_{2}$ some mechanistic insights could be gained. In Figure 1 e, an ${ }^{1} \mathrm{H}-\mathrm{NMR}$ (nuclear magnetic resonance) spectrum of the by-product mixture is shown. Using the organic compounds database (AIST) ${ }^{50}$ it was possible to identify the two components of the mixture as dimethylpropylamine (red markers) and dimethylprop-2-en-1-amine (blue markers). More detailed peak assignments within the spectra are provided in Figure S 3 and are also discussed in the SI. The formation of these two by- products was expected as prior decomposition studies of $\mathrm{Cu}(\mathrm{II})$ complexes using $\mathrm{Zn}(\mathrm{Et})_{2}$ gave the related by-products ethylene and ethane as well as the R-group coupling product, butane. ${ }^{41}$ For the example above, the R-coupled product would be N,N,N',N'-tetramethylhexane-1,6-diamine. While no species matching its AIST database entry (entry 6870) was found by ${ }^{1} \mathrm{H}-\mathrm{NMR}$, electron spray ionization mass spectrometry (ESIMS) analysis of the same crude product mixture confirmed its presence alongside the two prior identified tertiary amines (Figure $\mathbf{S}$ 4). Based on the ESI-MS, 1,6-diamine was found to be the major component, while the intensities for the tertiary amines were lower by far. A reason for that might be its preferential ionization in comparison to the other two by-products irrespective of its lower abundancy demonstrated by NMR. This lower abundancy might again originate from the lower volatility of the 1,6-diamine and potential thermal instability, both aspects making it more difficult to monitor it with simple trapping experiments. These initial results led us to consider all three amine species as reasonable candidates for by-products that might be formed in an actual ALD process utilizing $\mathrm{CoCl}_{2}$ (TMEDA) and $\mathrm{Zn}(\mathrm{DMP})_{2}$. As repeated by-product trapping and subsequent analysis by ${ }^{1} \mathrm{H}-\mathrm{NMR}$ and ESI-MS yielded similar results, none of the species was excluded from the mechanistic considerations described below. 


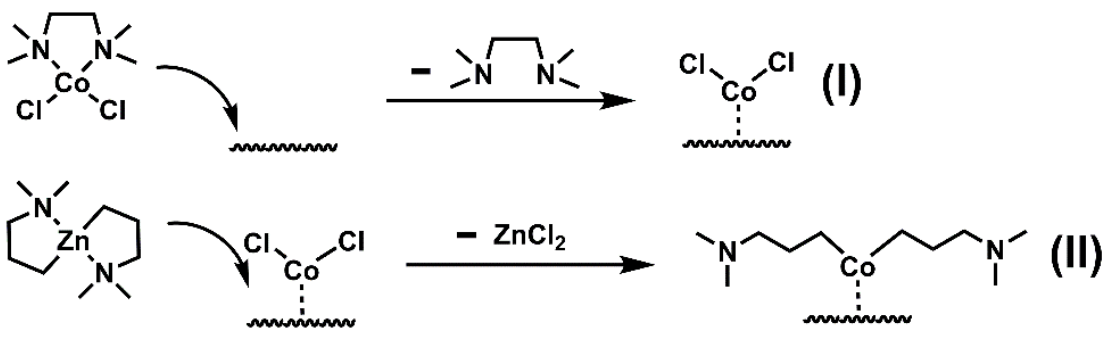

Pathway 1: $\beta$-Hydrogen Elimination

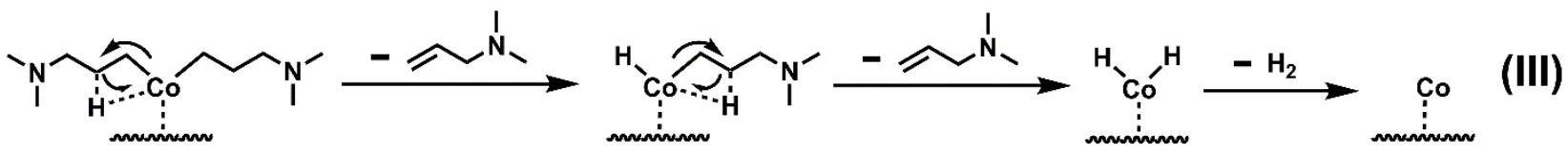

Pathway 2: $\beta$-Hydrogen Elimination \& Subsequent Hydrogen-Alkyl Recombination

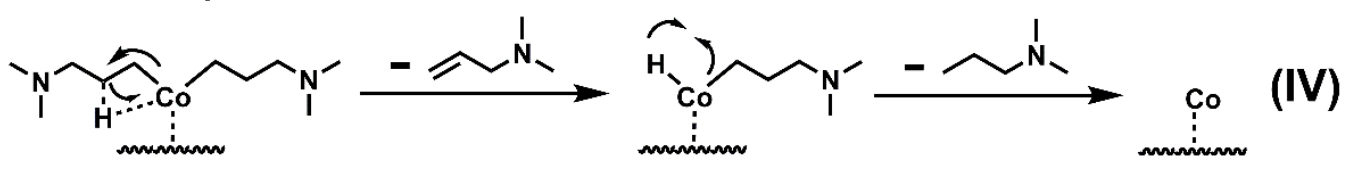

\section{Pathway 3: Concerted C-C Bond Formation}

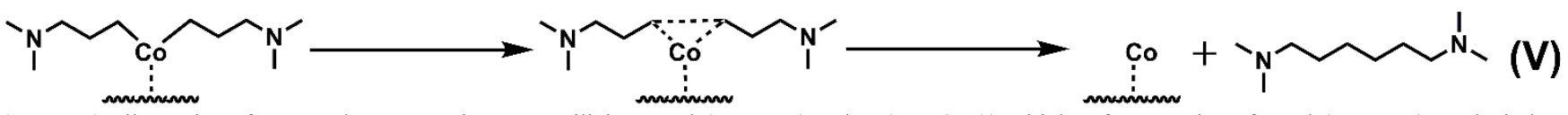

Scheme 2: Illustration of proposed ALD reaction steps utilizing $\mathrm{CoCl}_{2}(\mathrm{TMEDA})$ and $\mathrm{Zn}(\mathrm{DMP})_{2}$. (I) Initial surface reaction of CoCl $\mathrm{CMEDA}_{2}(\mathrm{TMEsults}$ in loss of TMEDA and $\mathrm{CoCl}_{2}$ physisorption. (II) Ligand exchange between $\mathrm{CoCl}_{2}$ and co-reagent (Hypothesis). (III) Successive $\beta$-hydrogen elimination within an intermediate Co aminoalkyl species, releases dimethylprop-2-en-1-amine followed by reductive elimination of hydrogen. (IV) The first $\beta$-hydrogen elimination could be followed by H-C recombination via reductive elimination, releasing dimethylpropylamine. (IV) Reductive elimination via C-C bond formation renders another reaction pathway.

\section{Surface Reaction Pathways}

The promising outcome of these initial reactivity tests motivated us to attempt ALD deposition experiments but also raised the question what the mechanisms behind thin film growth in the context of ALD would look like. The choice of precursors for Co ALD was narrowed down to $\mathrm{CoCl}_{2}$ (TMEDA) with either $\mathrm{Zn}(\mathrm{DMP})_{2}$ or $\mathrm{Zn}(\mathrm{Et})_{2}$ (TMEDA) as co-reactants. While both $\mathrm{Zn}$ compounds provided high thermal stability that we envisioned to aid overcoming the $\mathrm{Zn}$ contamination issue (as previously observed for $\mathrm{Zn}(\mathrm{Et})_{2}$ based $\mathrm{Cu} \mathrm{ALD}$ ); the following three aspects turned the balance in favor of $\mathrm{Zn}(\mathrm{DMP})_{2}$ : a) A ZnO ALD process and true ALD behavior was already reported for $\mathrm{Zn}(\mathrm{DMP})_{2}$. b) the CVD study on $\mathrm{Zn}(\mathrm{Et})_{2}$ (TMEDA) highlighted the intrinsic decomposition behavior of the compound on glass surfaces which rendered a vital drawback in our case as the F 120-ALD reactor, used in this study consisted of many glass parts; c) To obtain insights into the ALD deposition mechanisms and to rationalize the potential reaction pathways was a vital aim of this study. The neat reaction of $\mathrm{CoCl}_{2}$ (TMEDA) with $\mathrm{Zn}(\mathrm{DMP})_{2}$ provided the experimental evidence for the preferential formation of the by-products dimethylpropylamine, dimethylprop-2-en-1-amine and N,N,N',N'-tetramethylhexane-1,6-diamine with no indication of amino alkyl chlorides.

Consequently, a few, simplified elemental reaction steps and pathways are considered for the remaining precursor pair in the following (Scheme 2). These considerations are limited to intramolecular reactions on a metallic, non-oxidized substrate, namely an excerpt of the Co (111) surface. In the beginning, the reaction of gaseous $\mathrm{CoCl}_{2}$ (TMEDA) with the surface might be best described by physisorption of $\mathrm{CoCl}_{2}$ with release of the coordinating TMEDA as shown in (I) and suggested in recent
ALD literature. ${ }^{45}$ When $\mathrm{Zn}(\mathrm{DMP})_{2}$ is then pulsed in after a purge, it may engage in ligand exchange reactions with surface adsorbed $\mathrm{CoCl}_{2}$ producing an intermediate $\mathrm{Co}$ (II) aminoalkyl species and $\mathrm{ZnCl}_{2}$ (II). $\mathrm{ZnCl}_{2}$ would leave the surface as a volatile by-product. The proposed Co(II) aminoalkyl intermediate, that has been previously described to form in solution, ${ }^{47}$ could undergo several reaction pathways resulting in metallic Co. Hereby, the intramolecular reactions that can be envisioned for the Co surface species (see III - IV) are probably based on different reductive elimination reactions and are likely of competing nature. Successive, intramolecular $\beta$-hydrogen eliminations could release one of the tris-alkyl amine by-products and facilitate the formation of a geminal dihydrogen Co species that would reductively eliminate $\mathrm{H}_{2}$ (III). Alternatively, intramolecular $\mathrm{H}-\mathrm{C}$ bond formation via reductive elimination after an initial $\beta$-hydrogen elimination could produce the other tris-alkyl amine by-product (IV). Lastly, concerted C-C bond formation, again via reductive elimination, as reported for homogeneous Co catalysts in the liquid phase,${ }^{51}$ could generate a diamine byproduct $(\mathbf{V})$. Some additional, potential intermolecular reactions based on radical formation and recombination that may be considered in a more comprehensive study are further described in Figure $\mathbf{S} 5$. These considerations indicate that an ALD process based on such surface chemistry will likely differ from the idealized processes with only one specific surface reaction per half cycle: in the present case multiple competing reactions may take place. It is thus expected that deposition process parameters such as pressure and temperature strongly affect the surface chemistry and will amplify certain surface reactions. To test these initial mechanistic hypotheses and learn which of the pro- 
posed alkyl ligand elimination reactions might be more energetically favorable, detailed DFT calculations of these pathways were performed.

\section{DFT calculations}

The DFT considerations began with one $\mathrm{CoCl}_{2}$ molecule adsorbed on a model $\mathrm{Co}(111)$ surface, which is the structure after reaction $\mathbf{I}$ in the proposed mechanism in Scheme 2. The $\mathrm{Zn}$ aminoalkyl precursor $\mathrm{Zn}(\mathrm{DMP})_{2}$ then underwent interactions with the surface bound $\mathrm{CoCl}_{2}$. The flat mode in Figure 3 a, was the preferred binding mode, with an exothermic adsorption energy of $-0.46 \mathrm{eV}$; the less favorable upright mode had an exothermic adsorption energy of $-0.39 \mathrm{eV}$ (Figure 3 b). The computed reaction energies were $-0.60 \mathrm{eV}$ for ligand exchange and $-0.35 \mathrm{eV}$ for $\mathrm{ZnCl}_{2}$ loss, respectively. Hereby it is noteworthy, that the formation of the prior proposed intermediate $\mathrm{Co}(\mathrm{DMP})_{2}$ surface species is energetically favored and a reasonable starting point with the help of which the formation of Co in the actual ALD process can be rationalized.

a)
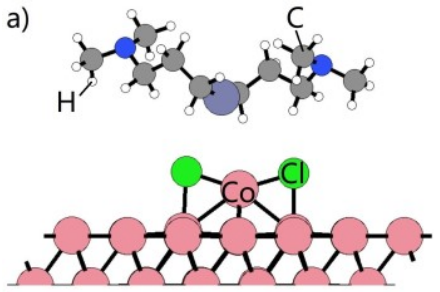

b)

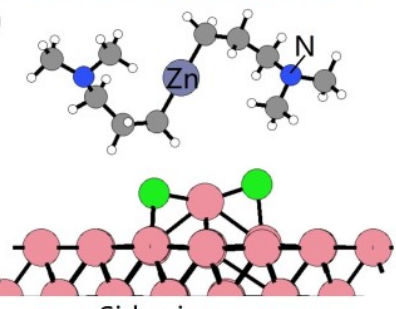

Side view

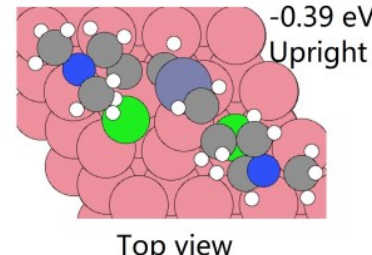

Figure 2: The adsorption of $\mathrm{Zn}(\mathrm{DMP})_{2}$ on $\mathrm{CoCl}_{2}-\mathrm{Co}(111)$ surface with (a) flat mode, and (b) upright mode.

We then computed the reaction energies for each elementary step via Pathway 1, Pathway 2 and Pathway 3 (c.f. Scheme 2) with one fold $\mathrm{CoCl}_{2}$ termination on $\mathrm{Co}(111)$ surface. For pathway 1 considering reductive elimination via $\beta$-hydrogen elimination, the computed reaction energy of the first $\mathrm{H}$ transfer to $\mathrm{Co}$ and formation of the by-product dimethlpropyl-2-en-1amine $\left(\mathrm{C}_{5} \mathrm{H}_{11} \mathrm{~N}\right)$ was found to be positive with a value of $+0.80 \mathrm{eV}$. The desorption of a second by-product equivalent and the second $\mathrm{H}$ transfer to Co continued to be endothermic. Finally, after $\mathrm{H}_{2}$ desorption, the computed reaction energy was as high as $+8.69 \mathrm{eV}$. The configurations of the elementary steps of Pathway 1 are shown in Figure S 6. For Pathway 2, which is based on reductive elimination via $\beta$-hydrogen elimination and subsequent $\mathrm{H}$-Alkyl recombination, the $\beta$-hydrogen elimination had the same positive reaction energies as in Pathway 1 . The reaction energy of $\mathrm{H}-\mathrm{Alkyl}$ recombination to form dimethylpropylamine $\left(\mathrm{C}_{5} \mathrm{H}_{12} \mathrm{~N}\right)$ was again positive with a value of $+4.24 \mathrm{eV}$. Finally, after desorption of accrued dimethylpropylamine, the computed energy cost was as high as $+4.38 \mathrm{eV}$. The configurations of the elementary steps of Pathway 2 are illustrated in Figure $\mathbf{S} 7$.

For Pathway 3, that factored in reductive elimination via concerted $\mathrm{C}-\mathrm{C}$ bond formation, the computed overall reaction en- ergies were exothermic, except for the desorption of the diamine by-product $\left(\mathrm{C}_{10} \mathrm{H}_{24} \mathrm{~N}_{2}\right)$ which had an energy cost of $+1.23 \mathrm{eV}$. The overall energy cost for this pathway was thus found to be considerably lower than for the other pathways. The configurations of the elementary steps of Pathway 3 are shown in Figure 3. Furthermore, the trend of the reaction energy for all three pathways is illustrated by Figure 4 a. These initial results implied that indeed reductive elimination through $\mathrm{C}-\mathrm{C}$ bond formation, as it had been observed in Co based liquid based catalysis, was the most viable pathway for Co ALD deposition for our $\mathrm{CoCl}_{2}$ (TMEDA) - $\mathrm{Zn}(\mathrm{DMP})_{2}$ process.

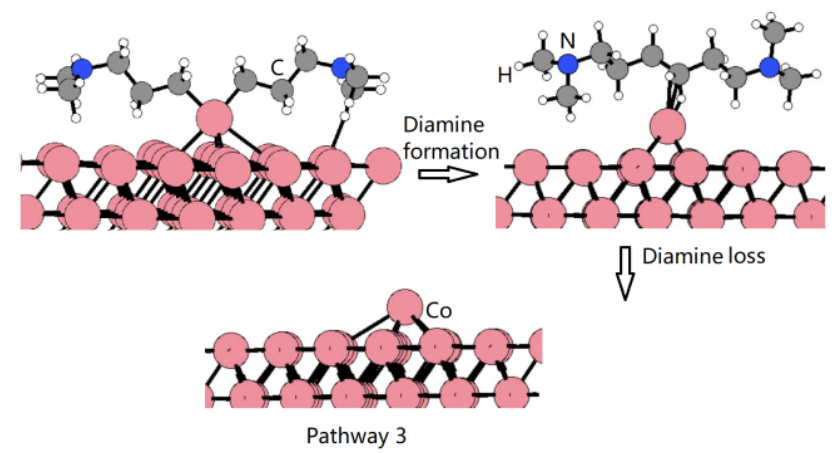

Figure 3: The configurations of elementary steps for pathway 3: First the intermediate $\mathrm{Co}(\mathrm{DMP})_{2}$ surface species is shown. Then, the state after concerted $\mathrm{C}-\mathrm{C}$ bond formation with the resulting diamine species still adsorbed to the Co atom is illustrated. Lastly, reductive elimination is completed by loss of the diamine by-product. Starting point for this was a Co(111) surface with onefold $\mathrm{CoCl}_{2}$ termination.

In a next step, we considered the effect of the surface coverage with $\mathrm{CoCl}_{2}$ onto the reaction energies of Pathways 1-3 by increasing the number of $\mathrm{CoCl}_{2}$ adsorbates on the $\mathrm{Co}$ (111) substrate to two. This model surface was then allowed to interact with two $\mathrm{Zn}(\mathrm{DMP})_{2}$ molecules consecutively. In the beginning, the first $\mathrm{Zn}$ aminoalkyl precursor $\mathrm{Zn}(\mathrm{DMP})_{2}$ had an exothermic interaction energy with a value of $-0.70 \mathrm{eV}$ (flat binding mode) with the twofold $\mathrm{CoCl}_{2}$ termination. The computed reaction energy of $\mathrm{ZnCl}_{2}$ loss was exothermic at the value of $-0.28 \mathrm{eV}$. These values were in close proximity to the prior calculations for one fold $\mathrm{CoCl}_{2}$ termination. We then computed the reaction energies for each elementary step via Pathway 1, Pathway 2 and Pathway 3 with two surface-bound $\mathrm{CoCl}_{2}$ adsorbates on the Co(111) surface. For Pathway 1 and Pathway 2, the computed reaction energy for the first $\beta$-hydrogen elimination was highly endothermic with a value of $+3.38 \mathrm{eV}$. Thus, no further calculations were performed for these two pathways and instead we focused on Pathway 3 . Here, the computed overall reaction energies were exothermic, except for the loss of by-product diamine. The results are shown in Figure $4 \mathbf{b}$. After the formation and desorption of the first by-product diamine, the computed reaction energy is endothermic with a small value of $+0.31 \mathrm{eV}$. An additional $\mathrm{Zn}(\mathrm{DMP})_{2}$ molecule was subsequently introduced to the system and its adsorption onto the Co(111) surface with one remaining $\mathrm{CoCl}_{2}$ and one terminal Co species found to be energetically strongly favored $(-0.98 \mathrm{eV})$. After ligand exchange and $\mathrm{ZnCl}_{2}$ loss, the reaction energy amounted to $0.52 \mathrm{eV}$. The computed reaction energies of formation and desorption of the second equivalent of diamine by-product were then determined to be $-0.22 \mathrm{eV}$ and $+0.82 \mathrm{eV}$, respectively. 

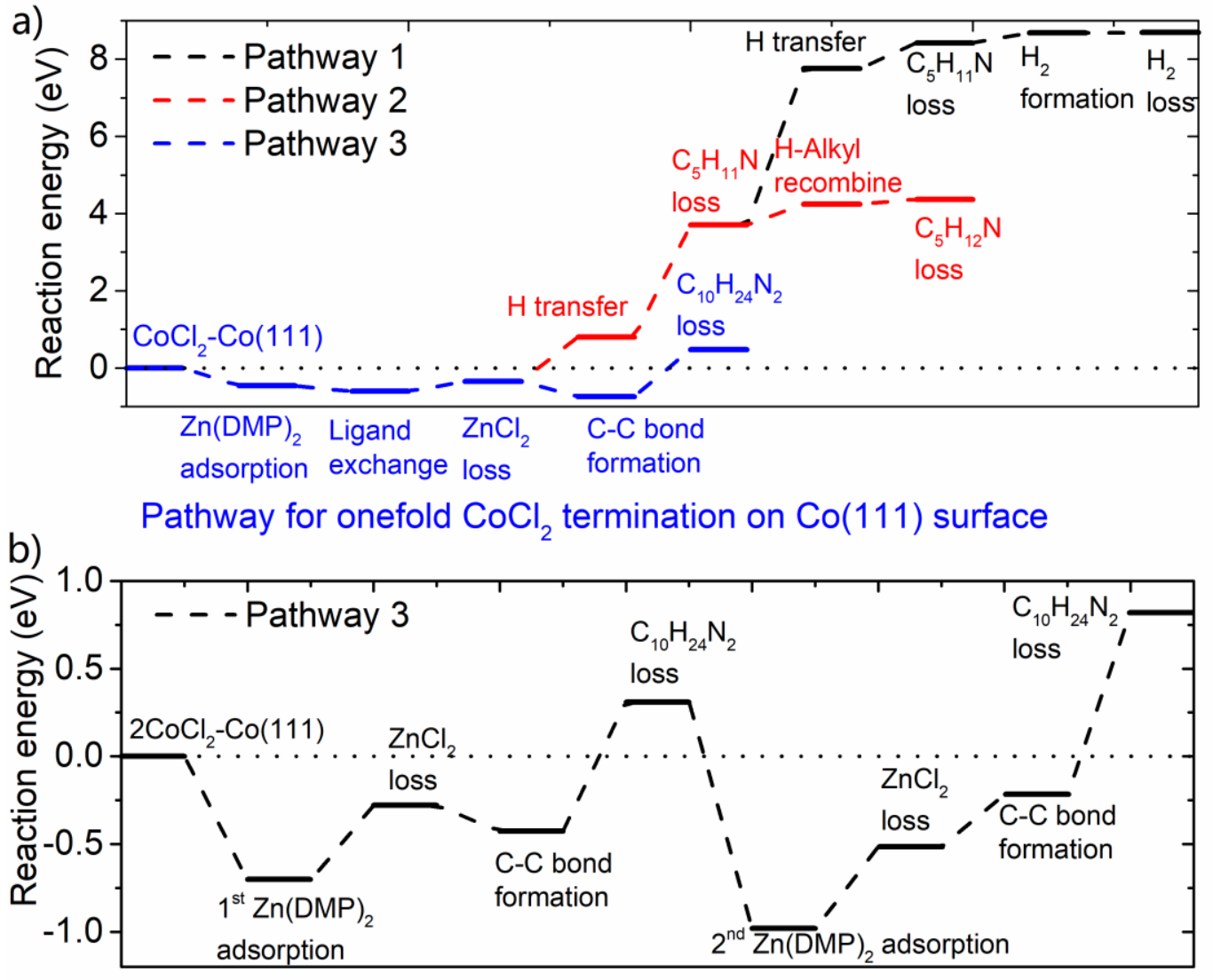

Pathway for twofold $\mathrm{CoCl}_{2}$ termination on $\mathrm{Co}(111)$ surface

Figure 4: Depiction of the plotted reaction energies for a) Pathways 1, 2, and 3 for a $\mathrm{Co}(111)$ surface with onefold $\mathrm{CoCl}_{2}$ termination and b) for Pathway 3 with twofold $\mathrm{CoCl}_{2}$ termination on a $\mathrm{Co}(111)$ surface. Labels indicate which elementary step has taken place with proceeding reaction path.

Complementary to the discussed surface reaction calculations, we probed the reaction Pathways 1-3 between $\mathrm{CoCl}_{2}$ and $\mathrm{Zn}(\mathrm{DMP})_{2}$ solely in the gas phase to be able to make a statement on the effect of the $\mathrm{Co}(111)$ substrate on the reaction energies. The results are summarized and graphically illustrated in Figure $\mathbf{S} \mathbf{8}$ in the supporting information. It was found that the reaction energies in the gas phase were around $2 \mathrm{eV}$ more endothermic in comparison to the surface calculations. However, Pathway 3 was still by far the least endothermic with a final reaction energy of around $2.2 \mathrm{eV}$ whereas it was around $6.0 \mathrm{eV}$ for Pathway 2 and over $9 \mathrm{eV}$ for Pathway 1. Matching the prior findings, the combined results imply that Pathway 3 is the most favorable reaction sequence to occur at typical operating temperatures between $140{ }^{\circ} \mathrm{C}$ and $225^{\circ} \mathrm{C}$ during the ALD process (see section ALD Process Development).

In a final step, we applied Bader charge analysis to the reaction sequences of pathways 1-3. Both scenarios, namely the occurrence of the reactions on a onefold $\mathrm{CoCl}_{2}$ terminated $\mathrm{Co}(111)$ surface and in the gas-phase were considered. An overview of the calculated charge transfers per elemental step is provided in Figure 5 and Figure $\mathbf{S} \mathbf{9}$, respectively. After ligand exchange between $\mathrm{Zn}(\mathrm{DMP})_{2}$ and $\mathrm{CoCl}_{2}$ took place and $\mathrm{ZnCl}_{2}$ is lost, two DMP $\left(\mathrm{C}_{5} \mathrm{H}_{12} \mathrm{~N}\right)$ ligands bond to the $\mathrm{Co}$ atom. In case of the gas phase scenario, a negative charge transfer from the metal atom to the DMP ligands of $-0.37 \mathrm{e}^{-}$was observed. For the onefold $\mathrm{Co}(\mathrm{DMP})_{2}$ terminated $\mathrm{Co}(111)$ surface, this charge transfer was found to amount to $-0.344 \mathrm{e}^{-}$. Besides, a small positive charge transfer of $+0.034 \mathrm{e}^{-}$from the Co substrate to one of the ligands and to the terminal $\mathrm{Co}$ atom occurred which gave evidence to the stabilization of the Co dialkyl intermediate through the surface (Figure 5). Further stabilizing charge transfers between the Co(111) surface and its different adsorbates became apparent for all other intermediates produced through the reaction sequences of Pathways 1-3. For Pathway 1 exemplarily (Figure 5 a), the surface was found to contribute with a negative charge transfer of $-0.08 \mathrm{e}^{-}$to the stabilization of the $\mathrm{CoH}(\mathrm{DMP})$ species after $\beta$-hydrogen elimination of a first dimethlpropyl-2-en-1amine equivalent. Congruously, a considerably larger negative charge transfer of $-0.28 \mathrm{e}^{-}$from the surface to the Co atom and its two hydride ligands was seen when ensuing $\beta$-hydrogen elimination had released another dimethlpropyl-2-en-1-amine equivalent. For Pathway 2 (Figure 5 b), the most significant charge transfer of the surface $\left(+0.116 \mathrm{e}^{-}\right)$was observed after $\mathrm{H}-$ Alkyl recombination through reductive elimination took place: Here, the terminal Co atom was already reduced to $\operatorname{Co}(0)$ and an equivalent of dimethylpropylamine was still in close proximity to the surface. For Pathway 3, the intermediate diamine species was found to be nearly not charged irrespective of the scenario. The computed transferred charges from the diamine to the Co atom was $-0.01 \mathrm{e}$ - for the Co terminated surface (Figure 5 c), and only slightly different with $0.028 \mathrm{e}$ - for the gas phase. The surface intermediate described by an already reduced $\operatorname{Co}(0)$ atom still coordinated by the diamine molecule was observed to benefit from positive charge transfer of the $\mathrm{Co}(111)$ substrate that amounted to $+0.18 \mathrm{e}^{-}$. It is noteworthy that for all pathways, Bader charge analysis showed a significant drop of the charge on the Co atom once the actual reduction step has occurred. 


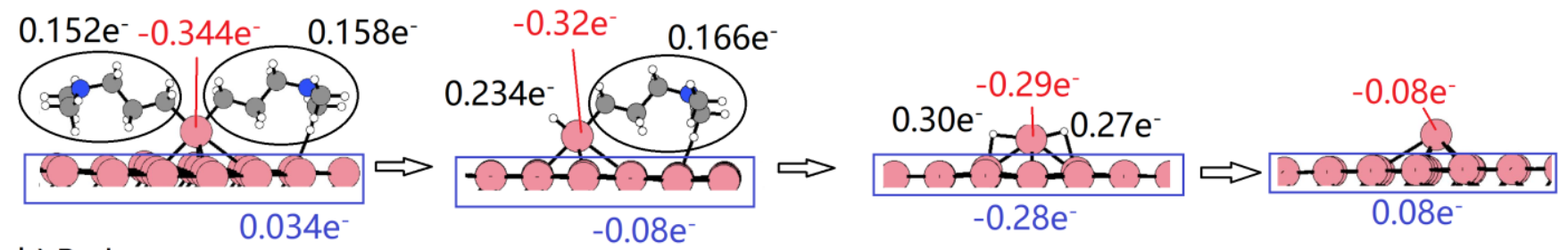

b) Pathway 2
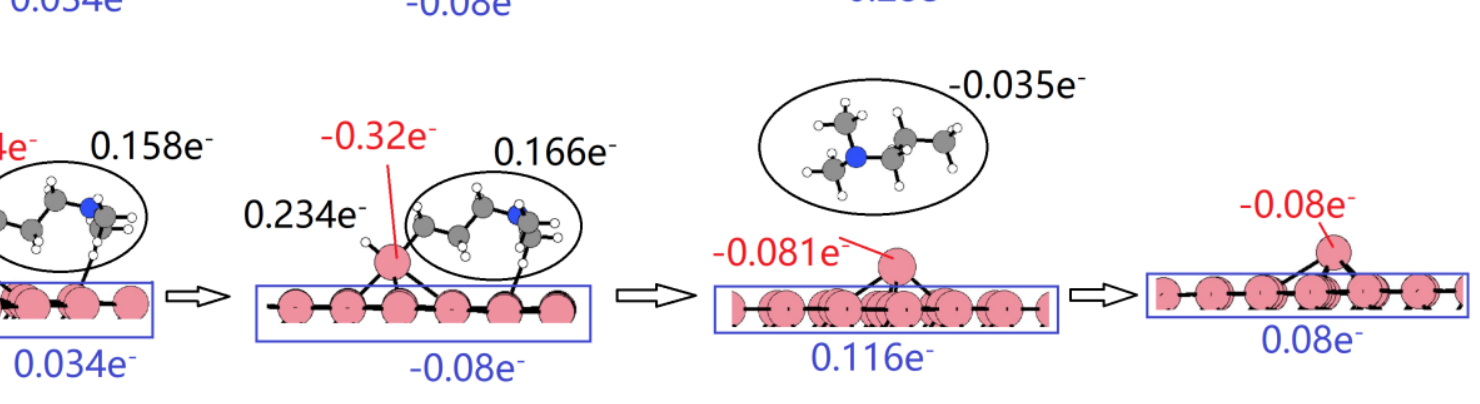

\section{c) Pathway 3}
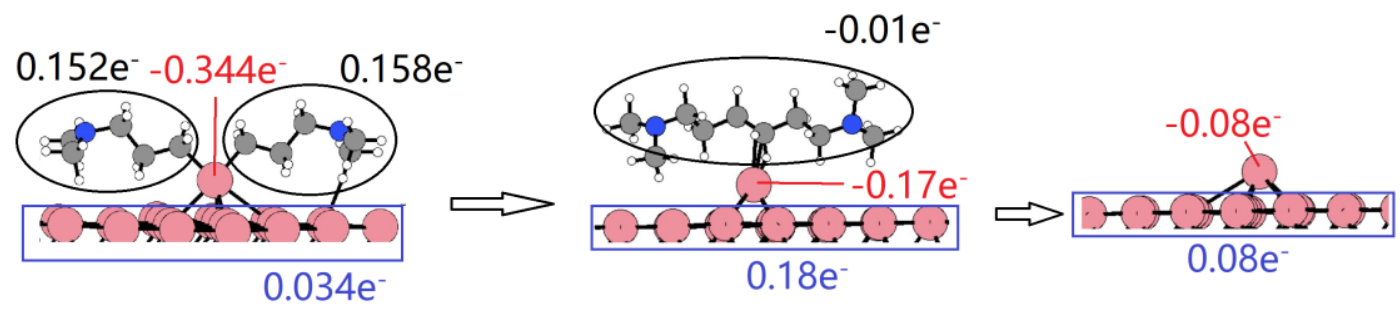

\section{Computed charge transfer for reactions of precursors on $\mathrm{Co}(111)$ substrate}

Figure 5: The computed charge transfers for all potential $\beta$-hydrogen elimination reaction sequences of one intermediate $\mathrm{Co}(\mathrm{II}) \mathrm{dialkyl}$ species on the Co(111) substrate: a) Pathway 1, b) Pathway 2, and c) Pathway 3. The charge transfer for by-products, Co atoms from different Co surface species and the Co(111) substrate are highlighted in black, red, and blue color, respectively.

Overall, Pathway 3 is not only the most straightforward way towards reduction of the surface intermediate $\operatorname{Co}(\mathrm{DMP})_{2}$ to elemental Co but Bader charge analysis illustrated that it minimized occurring charges best which in turn would favor this pathway over the others. This assessment is in accordance with the prior calculated reaction energies for the three pathways that rendered Pathway 3 as the least endothermic and most likely to occur during actual ALD depositions with the precursor combination $\mathrm{CoCl}_{2}$ (TMEDA) and $\mathrm{Zn}(\mathrm{DMP})_{2}$. The DFT findings are only perfunctorily in contrast to the initial reactivity tests and the by-product trapping. Pursuing our incipient suspicion on the instability of the 1,6-diamine by-product, we assessed the stability of all three amides theoretically and found the by-product generated via Pathway 3 to be the least stable. This and the fact that it is less volatile than its congeners owing to a higher molecular mass likely compromised on its detectability with our simple approach. As discussed subsequently in the thin film analysis section, we found this aspect to have implications on the Co thin film purity.

\section{ALD Process Development}

In the initial ALD process testing phase using $\mathrm{CoCl}_{2}$ (TMEDA) and $\mathrm{Zn}(\mathrm{DMP})_{2}$ as precursors, we observed unhindered growth of thin films with a metallic appearance on standard 2-inch $\mathrm{Si}(100)$ wafers with native oxide, as well as on the glass substrate holder. This direct film growth on non-metallic surfaces is in agreement with prior ALD studies by Väyrynen employing the same Co precursor for $\mathrm{Co}_{3} \mathrm{Sn}_{2}$ intermetallic films. ${ }^{46} \mathrm{Con}$ trasting this, the thermal ALD process developed by Kerrigan and co-workers with $\operatorname{Co}(\mathrm{DAD})_{2}$ was strongly inhibited on all surfaces except metallic ones. ${ }^{11}$ This suggested that unlike $\mathrm{Co}(\mathrm{DAD})_{2}, \mathrm{CoCl}_{2}$ (TMEDA) is capable of interacting with hydroxyl surface sites during the first pulse. The ALD process of $\mathrm{CoCl}_{2}$ (TMEDA) and $\mathrm{Zn}(\mathrm{DMP})_{2}$ was consequently investigated on $\mathrm{Si}(100)$ with native oxide. The growth behavior of the optimized process was also investigated for selected metal surfaces and Co thin film deposition was successful in all cases. These preliminary results are displayed and discussed in the supporting information (Section 12). The saturation behavior of precursors, the linear behavior of film thickness vs. number of cycles, and the influence of deposition temperature on the GPC were studied. Self-limiting behavior for $\mathrm{CoCl}_{2}$ (TMEDA) at $155^{\circ} \mathrm{C}$ and fixed $\mathrm{Zn}(\mathrm{DMP})_{2}$ pulse lengths of $5 \mathrm{~s}$ was observed after $6 \mathrm{~s}$ with a GPC of $0.3 \AA$ (Figure 6 a). The pulse lengths for the Co precursor are longer than those reported in prior studies, owing to variations in the reactor base pressure and configuration and the fact that $\mathrm{CoCl}_{2}$ (TMEDA) was evaporated at only $140{ }^{\circ} \mathrm{C}$ in this case, compared to $170{ }^{\circ} \mathrm{C}$ in earlier studies. ${ }^{46,52}$ For the more volatile $\mathrm{Zn}$ precursor (evaporated at $40{ }^{\circ} \mathrm{C}$ ), identical GPCs of $0.3 \AA$ were observed after pulses of $3 \mathrm{~s}$ or longer at $155^{\circ} \mathrm{C}$ and fixed $\mathrm{CoCl}_{2}$ (TMEDA) pulses of $6 \mathrm{~s}$ (Figure 6 b). 

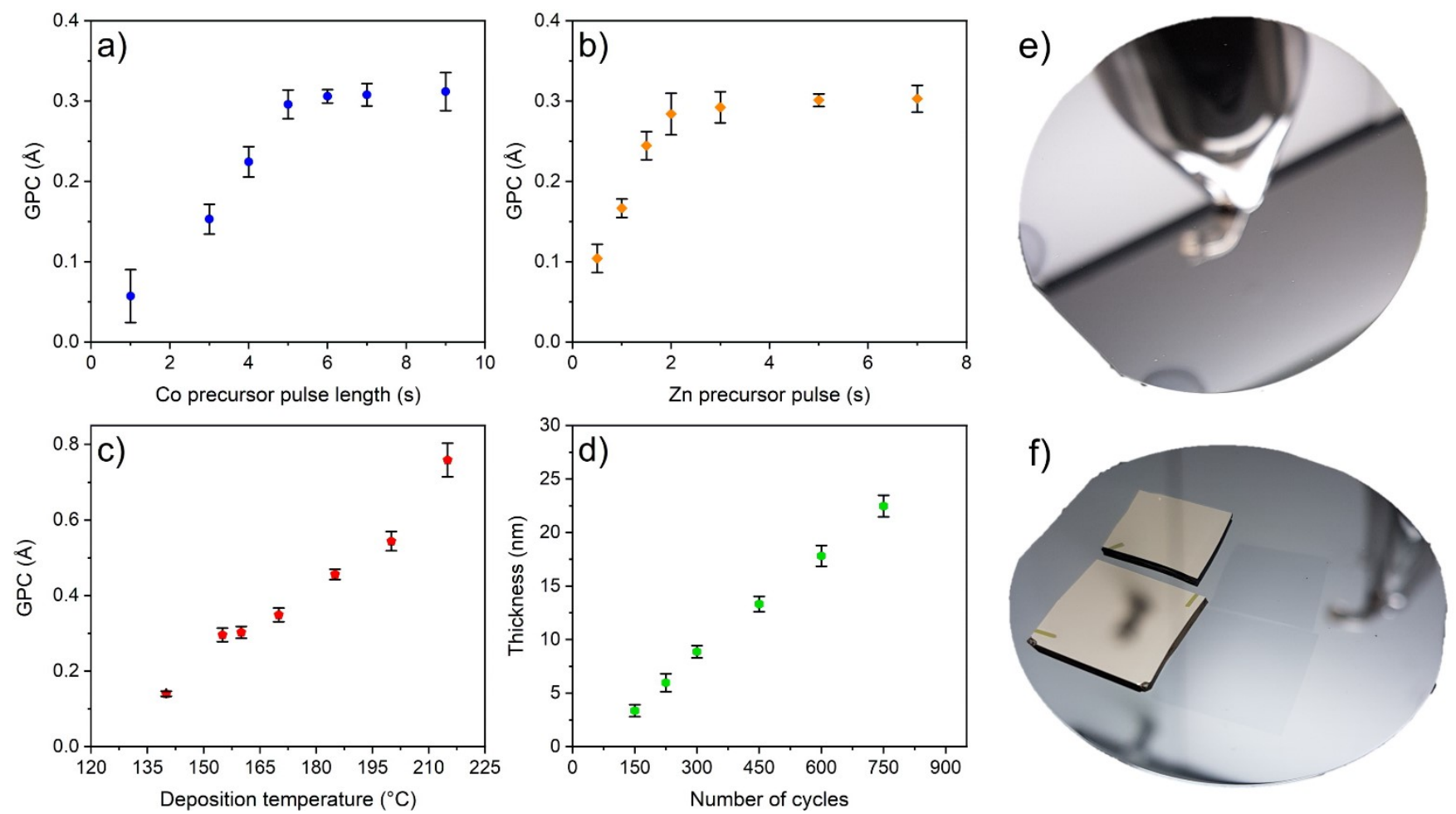

Figure 6: Characteristics of the ALD process using $\mathrm{CoCl}_{2}(\mathrm{TMEDA})$ and $\mathrm{Zn}(\mathrm{DMP})_{2}$ on $\mathrm{Si}(100)$ substrates with native oxide: a) $\mathrm{CoCl}_{2}(\mathrm{TMEDA})$ saturation study and b) $\mathrm{Zn}(\mathrm{DMP})_{2}$ saturation investigation at $155^{\circ} \mathrm{C}$ each. c) Temperature dependency of the GPC with precursor pulse times of $6 \mathrm{~s}$ for CoCl ${ }_{2}(\mathrm{TMEDA})$ and $3 \mathrm{~s}$ for $\mathrm{Zn}(\mathrm{DMP})_{2}$. d) Linear dependency of the film thickness on the applied number of cycles at $155^{\circ} \mathrm{C}$ utilizing the prior mentioned pulse parameters. e, f) Examples of coated 2-inch Si wafers on which process optimization was conducted. Non-coated areas correspond to those covered during the ALD process by either a substrate holder or where other substrates were placed on top.

For the optimized pulse lengths, purge durations were varied (Figure S 10). The chosen purge lengths of $30 \mathrm{~s}$ and $25 \mathrm{~s}$ were thus validated to be long enough to prevent unwanted intermixing of the two precursors. Significant influence of the deposition temperature on the GPC, with a narrow apparent "ALD window" identified between $155^{\circ} \mathrm{C}-165^{\circ} \mathrm{C}$ was observed (Figure 6 c). Reduction of the deposition temperature to $140{ }^{\circ} \mathrm{C}$ resulted in a GPC below $0.2 \AA$, and there was a nearly exponential GPC increase upon step-wise increase of the deposition temperature, terminating with a $0.77 \AA \mathrm{GPC}$ at $215^{\circ} \mathrm{C}$. The exponential increase in the GPC could originate from decomposition of $\mathrm{Zn}(\mathrm{DMP})_{2}$ above $170^{\circ} \mathrm{C}$ as suggested by Mai et al.. ${ }^{44}$ However, no $\mathrm{Zn}$ contamination within the deposits was found even above $170{ }^{\circ} \mathrm{C}$ (c.f. section thin film analysis) and under the specific deposition conditions and time scale $\mathrm{Zn}(\mathrm{DMP})_{2}$ might rather react with surface bound $\mathrm{CoCl}_{2}$ than undergo decomposition. Therefore, the strong dependency of the film growth may well be the consequence of changes of preferred thermal reaction pathways as suggested in the prior sections. Figure $6 \mathbf{d}$ shows a nearly ideal, linear trend between the number of cycles and film thickness at $155^{\circ} \mathrm{C}$, confirming the GPC of $0.3 \AA$ A. Finally, this process gave excellent uniformity of film growth on 2 inch wafers (Figure 6 e, f).

\section{Thin film analysis}

Selected metallic Co thin films were subjected to microscopy analysis (Figure 7). A series of scanning electron microscopy (SEM, upper row) and atomic force microscopy (AFM, bottom row) images were recorded for films of varied thickness grown at $155^{\circ} \mathrm{C}$ with optimized pulse parameters. The films had thicknesses between $4 \mathrm{~nm}$ (150 cycles) and $27 \mathrm{~nm}$ (900 cycles). For very thin films, the topography was found to be nearly featureless, while a small-grained texture evolved with successively increased number of cycles. The full SEM images are depicted in the SI (Figures S 11 - S 14). As expected for ALD layer-bylayer growth, the surfaces were found to be pinhole free and smooth. For example, the root-mean square roughness $\left(\mathrm{R}_{\mathrm{rms}}\right)$ of the $4 \mathrm{~nm}$ film was found to be $0.26 \mathrm{~nm}$ for a scan area of $1 \times 1 \mu \mathrm{m}^{2}$, mimicking the roughness of the underlying substrate. For the film grown with 900 cycles, the $\mathrm{R}_{\mathrm{rms}}$ value for the same area was determined to be $1.05 \mathrm{~nm}$. A survey on all $\mathrm{R}_{\mathrm{rms}}$ values determined based on $1 \times 1 \mu \mathrm{m}^{2}$ and $5 \times 5 \mu \mathrm{m}^{2}$ AFM scans showed a roughly linear $\left(\mathrm{R}^{2}=0.95\right)$ increase of roughness with thickness (Table S 1). Grazing incidence X-ray diffraction (GI-XRD), of 25 - $30 \mathrm{~nm}$ Co thin films grown at different temperatures showed the films to be amorphous, with no clear reflections identified. The absence of crystalline domains might either originate from an insufficiently high deposition temperature, the presence of impurities in the films, or an interplay of both aspects. Consecutively, selected thin films were subjected to combined, bulk-sensitive Rutherford backscattering spectrometry (RBS) and nuclear reaction analysis (NRA), as well as surface sensitive, depth profilometric X-ray photoemission spectroscopy (XPS) in order to obtain complementary insights in the overall composition of the thin films as well as the distribution of elements and their chemical states. The atomic bulk composition of films deposited between $140-215^{\circ} \mathrm{C}$, each having a thickness of $15-20 \mathrm{~nm}$, was determined by RBS/NRA (Table 1). The data are complemented by Figure S 15 that illustrates a representative RBS spectrum. Despite their metallic appearance, the Co thin films contained a notable level of carbon ( $\sim 25$ at. $\%)$ and oxygen $(\sim 5$ at. $\%)$ impurities while nitrogen and chlorine contaminant levels were below 3 at.\%. 

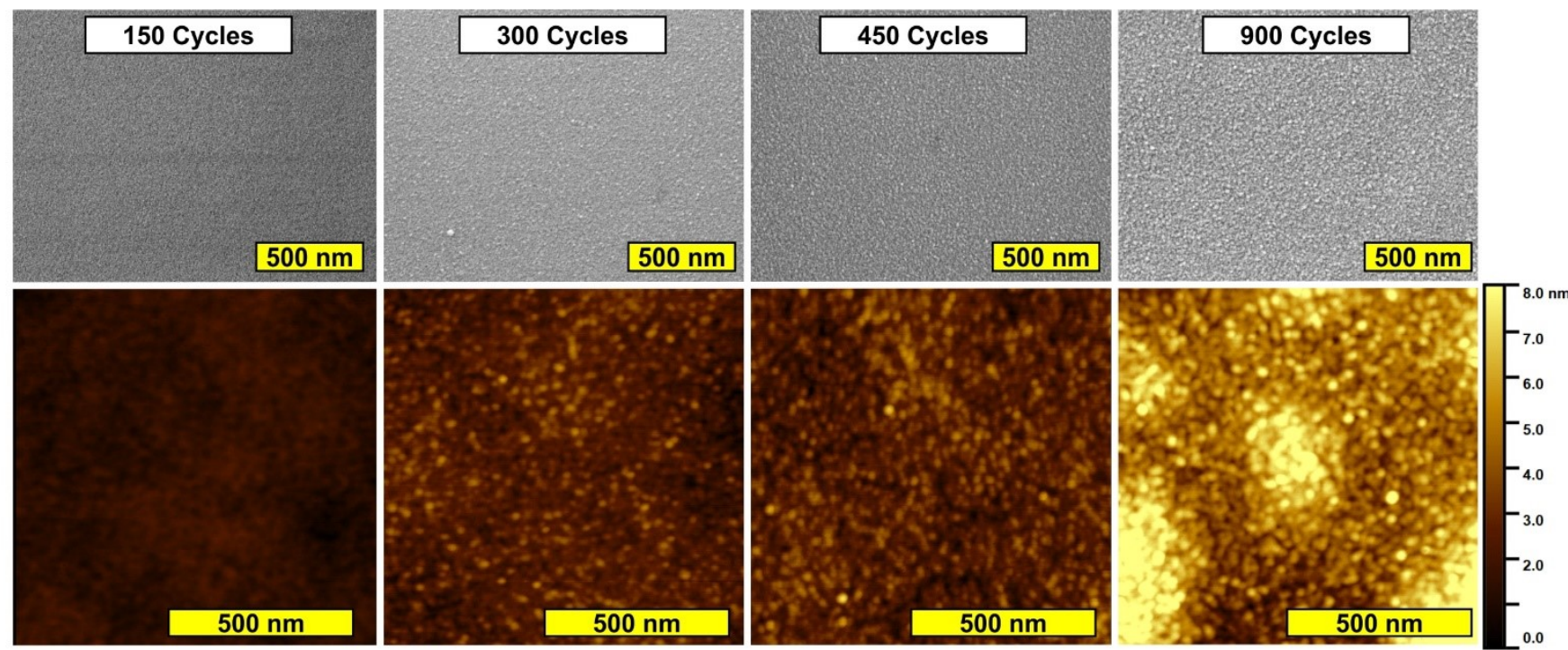

Figure 7: Complementary SEM (upper row) and AFM (bottom row) micrographs recorded for Co thin films with varying thicknesses (4 nm, 9 nm, $13.5 \mathrm{~nm}$ and $27 \mathrm{~nm}$ ) deposited at $155^{\circ} \mathrm{C}$ with optimized process parameters. For AFM, areas of $1 \times 1 \mu \mathrm{m}^{2}$ are shown and one scale is applied for all recordings.

The composition was found to be consistent and did not show strong temperature dependency, contrasting the temperature dependency of film growth. The presence of O ( $4.0-6.0$ at.\%) likely arises from exposure of the samples to the ambient prior to the measurements, which could not be avoided. Consequently, there was partial oxidation of the metallic $\mathrm{Co}^{53}$ and accumulation of some adventitious $\mathrm{C}$. The extent of $\mathrm{Zn}$ incorporation from the precursor $\mathrm{Zn}(\mathrm{DMP})_{2}$ (which replaced $\mathrm{Zn}(\mathrm{Et})_{2}$ to avoid the inclusion of $\mathrm{Zn}$ ) was measured to be very low ( $0.2-0.3$ at. $\%$ ) by RBS. The proximity of Co and $\mathrm{Zn}$ (with respect to the atomic number $Z$ ) and significant signal overlap (Figure S 15) called these $\mathrm{Zn}$ concentrations into question (see below). Composition was confirmed by an XPS depth profile study on a $20 \mathrm{~nm}$ Co thin film grown at $155^{\circ} \mathrm{C}$ (Figure 8 a). For this study, atomic concentrations were determined based on common signal fitting procedures for the $\mathrm{C} 1 \mathrm{~s}, \mathrm{Cl} 2 \mathrm{p}$, Co $2 \mathrm{p}$, $\mathrm{N} 1 \mathrm{~s}, \mathrm{O} 1 \mathrm{~s}$ and $\mathrm{Zn} 2 \mathrm{p}$ core level regions that are exemplarily shown in the SI (Section 11) ${ }^{54,55}$ The core level measurements were complemented by survey scans (Figure S 16). Initial, mild $\mathrm{Ar}^{+}$sputter steps (30 s per step, $1 \mathrm{kV}$ ) allowed to remove adventitious surface impurities. With increasing sputter time, the concentration of $\mathrm{C}$ gradually decreased until it equilibrated around 20 at.\% (in agreement with the values found from NRA) in the film bulk with a commensurate increase of the Co content to around 80 at.\%. Notably, Co had a metallic, zero oxidation state even in the immanent surface region as demonstrated by the stacked Co $2 p$ core level spectra (Figure 8 b). While the Co $2 p_{3 / 2}$ signal was slightly shifted to a higher binding energy for the as-introduced surface, its position was located at or in close proximity to $778.2 \mathrm{eV}$ which is characteristic for the zerovalent state of Co. ${ }^{54-56}$ The $\mathrm{O} 1 \mathrm{~s}$ core level measurements, shown alongside $\mathrm{C}$ 1s, $\mathrm{N}$ 1s and $\mathrm{Cl} 2$ p spectra in Figure $\mathbf{S}$ 17, revealed the presence of only organic oxygen species with a binding energy of $532.7 \mathrm{eV}$ on the surface, ${ }^{57}$ likely bonded to the adventitious carbon (for more detailed discussion see Section 11 of the SI). Most importantly, high resolution scans of the entire Zn 2p core level region (1010 - $1060 \mathrm{eV}$, Figure 8 c), demonstrated the absence of detectable $\mathrm{Zn}$ traces within the Co thin films. The absence was complementarily confirmed by a featureless Zn LMM Auger peak region (Figure $\mathbf{S}$ 16). Therefore, we are inclined to suggest the absence of $\mathrm{Zn}$ contamination in the Co ALD films. Thus, neither $\mathrm{Zn}(\mathrm{DMP})_{2}$ itself nor $\mathrm{Zn}$ byproducts from the second half cycle of the ALD process were considered to have caused the $\mathrm{C}, \mathrm{Cl}$ and $\mathrm{N}$ impurities. While the low $\mathrm{N}(\sim 1.0-2.0$ at.\%) and $\mathrm{Cl}(\sim 1.0-3.0$ at.\%) inclusions may have originated from unreacted surface adsorbed $\mathrm{CoCl}_{2}$ (TMEDA), the high C levels ( 24.0 - 28.0 at.\%; from RBS) could not be ascribed to adventitious $C$ only but from $\mathrm{C}$ embedded throughout the Co thin films.

Table 1: Compositional analysis of $15-20 \mathrm{~nm}$ Co thin films probed by RBS/NRA.

\begin{tabular}{|c|c|c|c|c|c|c|}
\hline \multirow{2}{*}{ Temperature $\left({ }^{\circ} \mathrm{C}\right)$} & \multicolumn{6}{|c|}{ Element Concentration (at.\%) ${ }^{\mathrm{a}}$} \\
\hline & $\mathrm{C}$ & $\mathrm{N}$ & $\mathrm{O}$ & $\mathrm{Cl}$ & $\mathrm{Co}$ & $\mathrm{Zn}^{\mathrm{b}}$ \\
\hline 140 & 25.9 & 1.1 & 4.6 & 3.0 & 65.1 & 0.3 \\
\hline 155 & 25.0 & 1.0 & 5.2 & 1.9 & 66.6 & 0.3 \\
\hline 170 & 23.8 & 2.1 & 5.5 & 2.0 & 66.4 & 0.3 \\
\hline 185 & 25.8 & 2.2 & 3.7 & 1.8 & 66.2 & 0.2 \\
\hline 200 & 25.0 & 2.2 & 5.7 & 1.2 & 65.7 & 0.2 \\
\hline 215 & 28.0 & 1.2 & 5.5 & 1.1 & 64.1 & 0.2 \\
\hline
\end{tabular}

${ }^{\mathrm{a}}$ In all cases, a possible error bar of \pm 1.5 at. $\%$ needs to be assumed. ${ }^{b}$ Determined concentrations are within the error margin. 

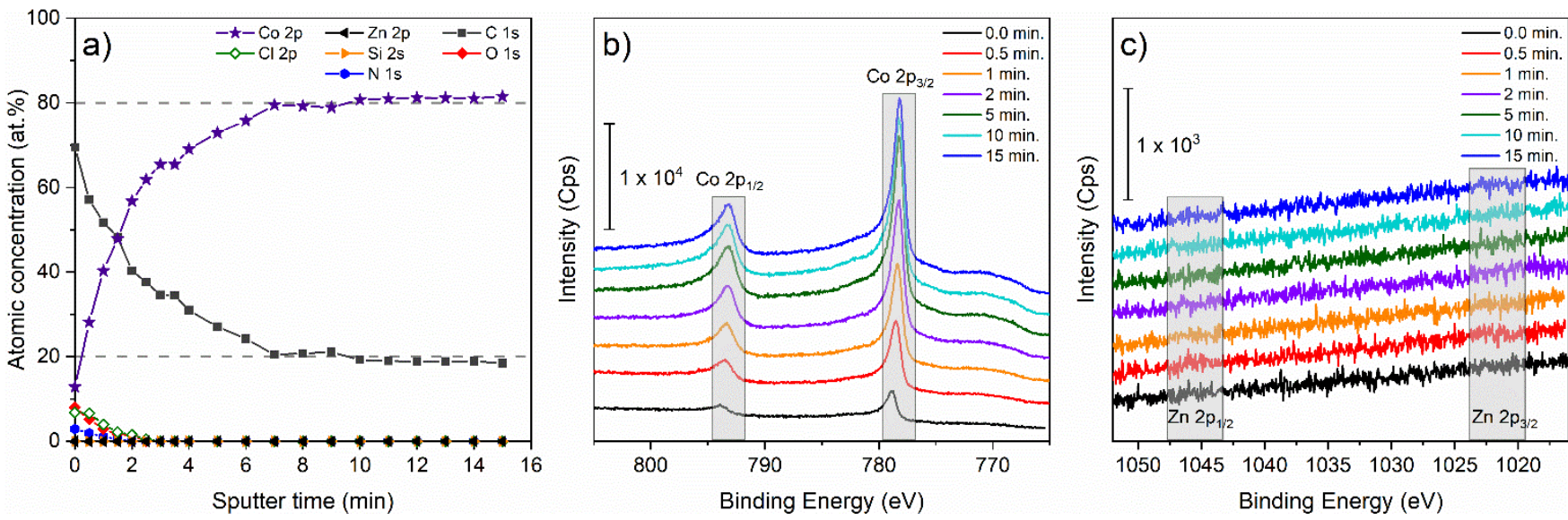

Figure 8: XPS analysis of a $20 \mathrm{~nm}$ thick Co thin film grown at $155{ }^{\circ} \mathrm{C}$ on $\mathrm{Si}(100)$ : a) Depth profile of the film with tracing of atomic concentrations of elements of interest. b) High resolution core level recordings of the Co $2 p$ region after selected sputter times. c) High resolution core level spectra of the $\mathrm{Zn} 2 \mathrm{p}$ region after selected sputter times evidencing the absence of $\mathrm{Zn}$. Gray areas in the core level spectra indicate expected signal positions.

Prior ALD studies employing $\mathrm{CoCl}_{2}$ (TMEDA) for the deposition of $\mathrm{CoO}^{52}$ and $\mathrm{Co}_{3} \mathrm{Sn}_{2}{ }^{46}$ with precursors such as $\mathrm{H}_{2} \mathrm{O}$ and $\mathrm{HSn}\left({ }^{\mathrm{t}} \mathrm{Bu}\right)_{3}$ yielded high purity thin films with no significant carbon incorporation, so the released TMEDA seems to be an unlikely source of $\mathrm{C}$ impurities. This leaves the intermediate $\mathrm{Co}(\mathrm{DMP})_{2}$ surface species and the by-products released from its reductive elimination to $\mathrm{Co}$ to have facilitated the $\mathrm{C}$ inclusion in the deposited films. With respect to this, our DFT calculations allow to postulate that the most likely formed by-product, namely N,N,N',N'-tetramethylhexane-1,6-diamine, may contribute to the $\mathrm{C}$ contents in the films. Additional experimental, and theoretical work is required to support these assumptions.

\section{Resistivity Measurements}

To determine the electrical resistivity of ALD deposited Co films, several $\sim 20 \mathrm{~nm}$ thick films were grown on Si substrates coated with $200 \mathrm{~nm}$ thermal $\mathrm{SiO}_{2}$. Hereby, optimized process parameters for a deposition temperature of $155^{\circ} \mathrm{C}$ were used. The resistivity of the ALD deposited Co films was found to be approximately $15-20 \mu \Omega \mathrm{cm}$ and is thus only slightly higher than the bulk resistivity of cobalt metal $(6.24 \mu \Omega \mathrm{cm})$ at $20{ }^{\circ} \mathrm{C},{ }^{58}$ indicating the growth of high performance metal films. The slightly increased resistivity values compared to bulk Co may be attributed to the carbon content in the films, since the film resistivity highly depends on both, the film thickness, and purity level. This is confirmed by the incrementally increased resistivity of the Co films in this work compared to the value $(13.6 \mu \Omega \mathrm{cm})$ reported by Kerrigan et al. ${ }^{11}$ on high purity (< $0.9 \%$ carbon, oxygen, nitrogen) 98 -nm-thick Co films deposited on $\mathrm{Pt}$, and on the other hand a clearly reduced resistivity compared to the PEALD deposited Co films based on $\mathrm{Co}(\mathrm{EtCp})_{2}(117 \mu \Omega \mathrm{cm})$ with an impurity content of $30-40 \%$ carbon, $15 \%$ nitrogen and $5 \%$ oxygen. ${ }^{27}$ The resistivity values determined in this work are in line with values obtained from various (PE)ALD processes summarized in the review of Kaloyeros et al. (Table 2) ${ }^{1}$ and enqueue themselves in the most upper performance segment. Two distinct beneficial characteristics of Co thin films deposited with this ALD process are obtaining near-bulk resistivity for Co films of small thickness that are closer to the dimensions relevant for applications and the direct, thermal growth of the films on non-metallic substrates. Both have rarely been demonstrated in prior studies to date and verify the high quality of the elemental Co films achieved by an innovative ALD processing route exploiting novel surface chemistry.

\section{Conclusion and Perspective}

This work has successfully shown an alternative approach towards the ALD of metallic Co thin films derived from initial precursor reactivity studies: using $\mathrm{Zn}$ aminoalkyls as reductants. Employing $\mathrm{CoCl}_{2}$ (TMEDA) and the intramolecularly stabilized $\mathrm{Zn}(\mathrm{DMP})_{2}$, precursor, a process was developed that outperformed earlier processes for metallic $\mathrm{Cu}$ with $\mathrm{Zn}(\mathrm{Et})_{2}$ in terms of $\mathrm{Zn}$ contamination. Film growth occurred with a GPC of $0.3 \AA$ on a variety of substrates at $155^{\circ} \mathrm{C}$ and $20 \mathrm{~nm}$ Co films directly deposited onto insulating $\mathrm{SiO}_{2}$ substrates showed promising resistivities as low as $15-20 \mu \Omega \mathrm{cm}$, competitive with bulk Co. However, high $\mathrm{C}$ contamination was a drawback impeding even better performance. A reasonable mechanism of film growth was proposed based on precursor reactivity studies which were validated by DFT calculations. It allowed to identify intramolecular reduction of intermediate Co aminoalkyl species as the potentially decisive step that facilitated the $\mathrm{C}$ incorporation in the films. Further research is necessary to understand if $\mathrm{Zn}$ dialkyls with differently functionalized ligands will enable ALD of purer Co thin films. The approach presented here may be generalized to the ALD of other transition metals using alkyl-based co-precursors that facilitate reduction through formation of highly reactive surface intermediates.

\section{Experimental and Computational Details}

Precursor synthesis: The synthesis of the oxygen and moisture sensitive compounds was performed under inert gas atmosphere using standard Schlenk techniques. All utilized solvents were purified and pre-dried by a MBraun solvent purification system (MBraun SPS). All compounds were stored, handled and prepared for analysis and reaction experiments under argon atmosphere (Air Liquide, 99.999 \%) in MBraun Labmaster 120 glove boxes. The starting reagents $\mathrm{CoCl}_{2}$ (anhydrous, $99.9 \%$ ), $\mathrm{ZnCl}_{2}$ (anhydrous, $99.9 \%$ ), Zn(Et) 2 (> 52 wt. \% Zn), and N,N,N',N'tetramethyletheylendiamine (TMEDA) $(99.0 \%)$ were bought from Sigma Aldrich and used as received. Precursors $\mathrm{CoCl}_{2}$ (TMEDA) ${ }^{52} \mathrm{Zn}(\mathrm{DMP})_{2},{ }^{44}$ and $\mathrm{Zn}(\mathrm{Et})_{2}$ (TMEDA) $)^{59}$ were synthesized in multigram scale following literature reported procedures. 
Reactivity pre-experiments: For the reactivity experiments of $\mathrm{CoCl}_{2}$ (TMEDA) with the three potential $\mathrm{Zn}$ dialkyl co-reactants, $1 \mathrm{mmol}$ of $\mathrm{CoCl}_{2}$ (TMEDA) and $1 \mathrm{mmol}$ of the respective $\mathrm{Zn}$ compound were filled into a Schlenk flask. Images were taken for optical monitoring. Subsequently, the neat mixtures were subjected to a two-step heat up treatment. In a first step, they were heated to $100^{\circ} \mathrm{C}$ in static vacuum for 1 minute and in the second step, they were heated up to $200{ }^{\circ} \mathrm{C}$ under active vacuum for additional one minute. For each step, photos were taken for documentation. Blind samples of $1 \mathrm{mmol} \mathrm{CoCl}$ (TMEDA) was subjected to the same treatment. Figure $\mathbf{S} \mathbf{1}$ in the SI summarizes the findings from this study. The solid residues obtained after heating were cooled down to room temperature and subjected to powder x-ray diffraction (PXRD) analysis. Measurements were conducted on a G670 diffractometer with an image plate detector (Huber, Rimsting, D) operating with Mo Ka radiation $(\lambda=0.07107 \mathrm{~nm})$. All diffractograms are depicted in Figure S 2. ${ }^{1} \mathrm{H}-\mathrm{NMR}$ (nuclear magnetic resonance) spectroscopy on the crude mixture of volatile by-products, trapped from the neat reaction of $\mathrm{CoCl}_{2}$ (TMEDA) and $\mathrm{Zn}(\mathrm{DMP})_{2}$ in a cooled receiver flask attached to the reaction vessel, was conducted on a Bruker Advance III $400 \mathrm{HD}$ instrument, and referenced to the internal tetra methyl silane (TMS) standard (TMS, $\delta=0.00 \mathrm{ppm}$ ). The AIST spectral database for organic compounds was used for compound identification (see entries 5416 and 6870)..$^{50}$ Electron spray ionization mass spectrometry (ESIMS) measurements were conducted on a Bruker Esquire 6000 instrument in chemical ionization mode with methanol as dilutant.

Computational details: All calculations were performed on the basis of periodic spin-polarized density functional theory (DFT) within a plane wave basis set and projector augmented wave (PAW) formalism, ${ }^{60}$ as implemented in the Vienna $a b$ initio simulation package (VASP 5.3) code. The generalized gradient approximation (GGA) with the parameterization of Perdew-Burke-Ernzerhof(PBE) was used for the exchange-correlation functional. ${ }^{61,62}$ The plane wave energy cutoff was set to be $400 \mathrm{eV}$. The convergence of energy and forces were set to be $1 \times 10^{-4} \mathrm{eV}$ and $0.01 \mathrm{eV} / \AA$, respectively. The bulk Co fcc crystal structure was optimized by simultaneously relaxing the ionic positions, cell volume and cell shape at a higher plane wave energy cutoff of $550 \mathrm{eV}$ and using a Monkhorst-Pack grid k-point mesh of $12 \times 12 \times 6 .{ }^{63}$ The resulting lattice constants are $\mathrm{a}=\mathrm{b}=2.49 \AA$, and $\mathrm{c}=4.03 \AA$ for Co bulk. A (4×4) supercell was used to model the $\mathrm{Co}(111)$ surface with a surface lattice of $\mathrm{a}=\mathrm{b}=9.94 \AA$. The vacuum region is up to $15 \AA$. The Co(111) substrate was modelled with a five-layer slab, with the bottom three layers fixed during the calculation and a k-point mesh of $3 \times 3 \times 1$ was used. The molecular geometries of precursor $\mathrm{Zn}(\mathrm{DMP})_{2}$ and by-products are relaxed in the same supercell as $\mathrm{Co}(111)$, with an energy cutoff of $400 \mathrm{eV}$ and Gamma point sampling. The van der Waals correction was applied with the PBE-D3 method to ensure an accurate description of the metal precursor adsorption energy. ${ }^{64}$ Charge transfers were analyzed with Bader charge analysis procedure. ${ }^{65,66}$ This was computed by $q$ (Bader) - $q$ (valence). The adsorption energy was calculated from:

$$
E_{a d}=E_{\text {tot }}-E_{\text {Cocl2/substrate }}-E_{A}
$$

where $\mathrm{E}_{\text {tot }}, \mathrm{E}_{\mathrm{CoCl} / \text { /substrate, }}$ and $\mathrm{E}_{A}$ were the energy of the slab with $\mathrm{Zn}(\mathrm{DMP})_{2}$ adsorption, the slab model for $\mathrm{CoCl}_{2}$ and $\mathrm{Co}(111)$ substrate, and isolated $\mathrm{Zn}(\mathrm{DMP})_{2}$, respectively.
ALD Experiments: All depositions were carried out in an ASM Microchemistry F-120 reactor with interior satellite geometry and a base pressure of 3.0 mbar. Process optimization was performed on 2 inch $\mathrm{Si}(100)$ substrates with native oxide $\left(\mathrm{SiO}_{\mathrm{x}}, \sim 2 \mathrm{~nm}\right)$. Additional depositions were carried out on $\approx$ $1 \mathrm{~cm} \times 1 \mathrm{~cm}$ large Si substrates with $\approx 30 \mathrm{~nm}$ of $\mathrm{Au}, \mathrm{Pt}$ and $\mathrm{Al}_{2} \mathrm{O}_{3}$ on top (Metallic films were deposited by sputtering, while the oxide was grown by thermal ALD). For standard depositions ranging from $100-900$ cycles, $200 \mathrm{mg}$ of $\mathrm{CoCl}_{2}$ (TMEDA) and $300 \mathrm{mg}$ of $\mathrm{Zn}$ (DMP) 2 were used per deposition. The Co precursor was kept at $140^{\circ} \mathrm{C}$ while the $\mathrm{Zn}$ precursor was kept at $40^{\circ} \mathrm{C}$. $\mathrm{Zn}(\mathrm{DMP})_{2}$ and $\mathrm{CoCl}_{2}$ (TMEDA) were spatially separated with a temperature buffer zone in between to ensure constant evaporation temperatures during the deposition process. The volatilization of both precursors to the substrate was assisted by an active $\mathrm{N}_{2}$ flow (Air Liquide $99.995 \%$ ) of $300 \mathrm{sccm}$. Depositions were carried out in a temperature window of $140{ }^{\circ} \mathrm{C}-215^{\circ} \mathrm{C}$ and an optimized pulse-purge recipe of $6 \mathrm{~s}$ Co precursor pulse, $30 \mathrm{~s}$ of $\mathrm{N}_{2}$ purge ( $300 \mathrm{sccm}$ ), $3 \mathrm{~s} \mathrm{Zn}$ precursor pulse and again $25 \mathrm{~s}$ of $\mathrm{N}_{2}$ purge was applied.

Thin film analysis: The thickness of the deposited Co thin films was determined from X-ray reflectometry (XRR) measurements carried out on a Bruker AXS-D8 Discovery diffractometer (Bruker cooperation) $(\mathrm{Cu} \mathrm{K} \alpha$ radiation with $\lambda=1.5418 \AA$ ) in $\theta-2 \theta$ locked coupled mode. Thicknesses were further verified by comparison of the recorded XRR curves with simulated and fitted curves using Bruker LEPTOS software. A two layer model, $\left(\mathrm{Co} / \mathrm{SiO}_{2} / \mathrm{Si}(100)\right)$, was considered as the basis. Atomic force microscopy (AFM) measurements were performed using a Nanoscope Multimode V microscope from Digital Instruments operating in tapping mode. Scanning electron microscopy (SEM) was performed using a field-emission scanning electron microscope (JEOL JSM-7200F). The top view images (magnification x70.000) were recorded using $20 \mathrm{kV}$ acceleration voltage with a secondary electron detector (SED).

The bulk composition of Co thin films deposited on various substrates was determined by Rutherford backscattering spectrometry (RBS) in combination with nuclear reaction analysis (NRA) at the 4-MeV tandem accelerator facility RUBION at Ruhr University Bochum. Standard RBS was executed with a ${ }^{4} \mathrm{He}^{+}$ion beam of $2.0 \mathrm{MeV}$, while a $4 \mathrm{MeV}$ ion beam was employed for experiments where $\mathrm{Co}$ and $\mathrm{Zn}$ signal differentiation was attempted. In all cases, samples were tilted at an angle of $7^{\circ}$, whereas backscattering particles were detected at an angle of $160^{\circ}$ with respect to the beam axis. NRA was performed using $\mathrm{a}^{2} \mathrm{H}^{+}$ion beam of $1 \mathrm{MeV}$. Emitted protons were detected at an angle of $135^{\circ}$ relative to the incoming beam axis. The SIMNRA program was employed for raw data processing and analysis.$^{67} \mathrm{X}$-ray photoelectron spectroscopy (XPS) for surface and depth profile compositional analysis was carried out on a PHI 5000 instrument. The kinetic energy of electrons was analyzed with a spherical Leybold EA-10/100 analyzer using a pass energy of $18 \mathrm{eV}$. The samples were analyzed by a combination of survey scans and core level scans for peaks of interest. Step widths were adjusted to $0.5 \mathrm{eV}$ for each survey scan and $0.05 \mathrm{eV}$ for the core level scans. All binding energies of $\mathrm{Zn} 2 \mathrm{p}$, Co $2 p, C l 2 p, O$ ss, N 1s and C 1s were referenced to the fermi edge position. The analysis chamber pressure was maintained at $<10^{-7}$ mbar. Depth profile analysis of a $25 \mathrm{~nm}$ thick film grown at $155^{\circ} \mathrm{C}$ was realized by a succession of measurement and sputter steps. Hereby, sputtering with $\mathrm{Ar}^{+}$was limited to $30 \mathrm{~s}$ per step and $1 \mathrm{kV}(2 \times 2)$ to minimize preferential sputter 
effects. The deconvolution analysis was completed with a Shirley background processing and Gaussian functions using UniFit 2017 software.

Resistivity measurements: Co thin films $(\sim 20 \mathrm{~nm})$ were grown on $1.5 \mathrm{~cm} \times 1.5 \mathrm{~cm} \mathrm{Si}$ substrates with $\sim 200 \mathrm{~nm} \mathrm{SiO}{ }_{2}$ on top generated through thermal oxidation. The electrical measurements were performed at room-temperature using a Signatone four-point probe in combination with a Keithley 2615 Source Measurement Unit. The film resistivity was calculated based on the film thickness additionally determined by a spectroscopic ellipsometer (Sentech SE 800) and the sheet resistance.

\section{ASSOCIATED CONTENT}

\section{Supporting Information.}

Reactivity pre-experiments; Additional mechanistic considerations, ALD process purge studies; Additional film characterization data (AFM, SEM, RBS/NRA, XPS); Film growth data on alternative substrates, Additional computational details. This material is available free of charge via the Internet at http://pubs.acs.org.

\section{AUTHOR INFORMATION}

\section{Corresponding Author}

Anjana Devi

Email: anjana.devi@rub.de

\section{Author Contributions}

The manuscript was written through contributions of all authors. All authors have given approval to the final version of the manuscript.

\section{Funding}

The main funding for the research at RUB was granted by the Deutsche Forschungsgemeinschaft (DFG) SFB-TR-87 (B4), and DE-790/18-1) and BMBF (ForMikro-FlexTMDSense: 16ES1096K). The work at Tyndall was funded by the Science Foundation Ireland-Natural National Science Foundation China SFI-NSFC Partnership program through the project NITRALD, Grant number 17/NSFC/5279.

\section{Notes}

The authors declare no competing financial interest.

\section{ACKNOWLEDGMENT}

The authors from RUB acknowledge Marvin Heller (ESI-MS), Dr. Bert Mallick (PXRD), Thomas Berning (SE) and Sebastian Beer (SEM) for supporting this work. D.Z. thanks Goran Bačić for fruitful discussions. D.Z. acknowledges the funding and financial support from the German Academic Exchange Service (DAAD-1-year fellow program) and the Fond of Chemical Industries (Kekulé fellowship) for his $\mathrm{PhD}$ fellowship. $\mathrm{AD}$ and $\mathrm{DZ}$ acknowledge $\mathrm{ZGH}$ (RUB) for using its facilities. Support and computational resources from the Irish Centre for High End Computing and from the SFI funded Tyndall computing resources are gratefully acknowledged. J.L. acknowledges that part of the results of this research have been achieved using the DECI resource BEM cluster based in Poland at Wroclaw Centre for Networking and Supercomputing with support from the PRACE.

\section{References}

(1) Kaloyeros, A. E.; Pan, Y.; Goff, J.; Arkles, B. Editors' Choice-Review-Cobalt Thin Films: Trends in Processing Technologies and Emerging Applications. ECS J. Solid State Sci. Technol. 2019, 8, P119-P152.

(2) Ivanova, A. R.; Nuesca, G.; Chen, X.; Goldberg, C.; Kaloyeros, A. E.; Arkles, B.; Sullivan, J. J. The Effects of Processing Parameters in the Chemical Vapor Deposition of Cobalt from Cobalt Tricarbonyl Nitrosyl. J. Electrochem. Soc. 1999, 146, 2139-2145.

(3) Andreev, A. S.; d'Espinose de Lacaillerie, J.-B.; Lapina, O. B.; Gerashenko, A. Thermal stability and hep-fcc allotropic transformation in supported Co metal catalysts probed near operando by ferromagnetic NMR. Physical chemistry chemical physics : PCCP 2015, 17, 1459814604 .

(4) Bekiaris, N.; Wu, Z.; Ren, H.; Naik, M.; Park, J. H.; Lee, M.; Ha, T. H.; Hou, W.; Bakke, J. R.; Gage, M. et al. Cobalt fill for advanced interconnects. In 2017 IEEE International Interconnect Technology Conference (IITC); pp 1-3.

(5) Hung, R.; Park, J. H.; Ha, T. H.; Lee, M.; Hou, W.; Lei, J.; Bakke, J. R.; Sharma, S.; Sharma, K. R.; Kim, N. S. et al. Extreme Contact Scaling with Advanced Metallization of Cobalt. In 2018 IEEE International Interconnect Technology Conference (IITC); pp 30-32.

(6) Fert, A. Advantages of CNT and graphene for spintronics. In 8 th International Vacuum Electron Sources Conference and Nanocarbon (2010 IVESC); p 1

(7) Chang, C. S.; Kostylev, M.; Ivanov, E. Metallic spintronic thin film as a hydrogen sensor. Appl. Phys. Lett. 2013, 102, 142405.

(8) Onur Avci, C.; Garello, K.; Mihai Miron, I.; Gaudin, G.; Auffret, S.; Boulle, O.; Gambardella, P. Magnetization switching of an $\mathrm{MgO} / \mathrm{Co} / \mathrm{Pt}$ layer by in-plane current injection. Appl. Phys. Lett. 2012, 100, 212404.

(9) Vo-Van, C.; Kassir-Bodon, Z.; Yang, H.; Coraux, J.; Vogel, J.; Pizzini, S.; Bayle-Guillemaud, P.; Chshiev, M.; Ranno, L.; Guisset, V. et al. Ultrathin epitaxial cobalt films on graphene for spintronic investigations and applications. New J. Phys. 2010, 12, 103040.

(10) Gil, W.; Görlitz, D.; Horisberger, M.; Kötzler, J. Magnetoresistance anisotropy of polycrystalline cobalt films: Geometrical-size and domain effects. Phys. Rev. B 2005, 72, 1039.

(11) Kerrigan, M. M.; Klesko, J. P.; Winter, C. H. Low Temperature, Selective Atomic Layer Deposition of Cobalt Metal Films Using Bis(1,4-ditert -butyl-1,3-diazadienyl)cobalt and Alkylamine Precursors. Chem. Mater. 2017, 29, 7458-7466.

(12) Dorovskikh, S. I.; Hairullin, R. R.; Sysoev, S. V.; Kriventsov, V. V.; Panin, A. V.; Shubin, Y. V.; Morozova, N. B.; Gelfond, N. V.; Korenev, S. V. MOCVD growth and study of magnetic Co films. Surface Engineering 2015, 32, 8-14.

(13) Georgi, C.; Hildebrandt, A.; Waechtler, T.; Schulz, S. E.; Gessner, T.; Lang, H. A cobalt layer deposition study: Dicobaltatetrahedranes as convenient MOCVD precursor systems. J. Mater. Chem. C 2014, $2,4676$. (14) Georgi, C.; Hapke, M.; Thiel, I.; Hildebrandt, A.; Waechtler, T.; Schulz, S. E.; Lang, H. Half-sandwich cobalt complexes in the metal-organic chemical vapor deposition process. Thin Solid Films 2015, 578, $180-184$.

(15) Hamilton, J. A.; Pugh, T.; Johnson, A. L.; Kingsley, A. J.; Richards, S. P. Cobalt(I) Olefin Complexes: Precursors for Metal-Organic Chemical Vapor Deposition of High Purity Cobalt Metal Thin Films. Inorganic chemistry 2016, 55, 7141-7151.

(16) Chioncel, M. F.; Haycock, P. W. Structural Characterization of Cobalt Thin Films Grown by Metal-Organic CVD. Chem. Vap. Deposition 2005, 11, 235-243.

(17) Feng, J.; Gong, X.; Lou, X.; Gordon, R. G. Direct-Liquid-Evaporation Chemical Vapor Deposition of Nanocrystalline Cobalt Metal for Nanoscale Copper Interconnect Encapsulation. ACS applied materials \& interfaces 2017, 9, 10914-10920.

(18) Yang, J.; Li, K.; Feng, J.; Gordon, R. G. Direct-liquid-evaporation chemical vapor deposition of smooth, highly conformal cobalt and cobalt nitride thin films. J. Mater. Chem. C 2015, 3, 12098-12106.

(19) Nadhom, H.; Lundin, D.; Rouf, P.; Pedersen, H. Chemical vapor deposition of metallic films using plasma electrons as reducing agents. Journal of Vacuum Science \& Technology A 2020, 38, 33402.

(20) Marichy, C.; Bechelany, M.; Pinna, N. Atomic layer deposition of nanostructured materials for energy and environmental applications. $A d-$ vanced materials (Deerfield Beach, Fla.) 2012, 24, 1017-1032.

(21) George, S. M. Atomic layer deposition: an overview. Chemical reviews 2010, 110, 111-131. 
(22) Cremers, V.; Puurunen, R. L.; Dendooven, J. Conformality in atomic layer deposition: Current status overview of analysis and modelling. $A p$ plied Physics Reviews 2019, 6, 21302.

(23) Leskelä, M.; Ritala, M. Atomic layer deposition chemistry: recent developments and future challenges. Angewandte Chemie (International ed. in English) 2003, 42, 5548-5554.

(24) Boris, D. R.; Wheeler, V. D.; Nepal, N.; Qadri, S. B.; Walton, S. G.; Eddy, C. R. The role of plasma in plasma-enhanced atomic layer deposition of crystalline films. Journal of Vacuum Science \& Technology A 2020, 38, 40801.

(25) Park, J.; Lee, H.-B.-R.; Kim, D.; Yoon, J.; Lansalot, C.; Gatineau, J.; Chevrel, H.; Kim, H. Plasma-enhanced atomic layer deposition of Co using $\mathrm{Co}(\mathrm{MeCp}) 2$ precursor. Journal of Energy Chemistry 2013, 22, 403407.

(26) Yoon, J.; Lee, H.-B.-R.; Kim, D.; Cheon, T.; Kim, S.-H.; Kim, H. Atomic Layer Deposition of Co Using N2H2 Plasma as a Reactant. J. Electrochem. Soc. 2011, 158, H1179.

(27) Zhu, B.; Ding, Z.-J.; Wu, X.; Liu, W.-J.; Zhang, D. W.; Ding, S.-J. Plasma-Enhanced Atomic Layer Deposition of Cobalt Films Using $\mathrm{Co}(\mathrm{EtCp}) 2$ as a Metal Precursor. Nanoscale research letters 2019, 14, 76. (28) Lee, K.; Kim, K.; Park, T.; Jeon, H.; Lee, Y.; Kim, J.; Yeom, S. Characteristics of Ti-Capped Co Films Deposited by a Remote Plasma ALD Method Using Cyclopentadienylcobalt Dicarbonyl. J. Electrochem. Soc. 2007, 154, H899.

(29) Kim, J.-M.; Lee, H.-B.-R.; Lansalot, C.; Dussarrat, C.; Gatineau, J.; Kim, H. Plasma-Enhanced Atomic Layer Deposition of Cobalt Using Cyclopentadienyl Isopropyl Acetamidinato-Cobalt as a Precursor. Jpn. J. Appl. Phys. 2010, 49, 05FA10.

(30) Kim, K.; Lee, K.; Han, S.; Park, T.; Lee, Y.; Kim, J.; Yeom, S.; Jeon, H. Comparison of Co Films Deposited by Remote Plasma Atomic Layer Deposition Method with Cyclopentadienylcobalt Dicarbonyl $[\mathrm{CpCo}(\mathrm{CO}) 2]$ and Dicobalt Octacarbonyl [Co 2 (CO) 8 ]. Jpn. J. Appl. Phys. 2007, 46, L173-L176.

(31) Knoops, H. C. M.; Faraz, T.; Arts, K.; Kessels, W. M. M. Status and prospects of plasma-assisted atomic layer deposition. Journal of Vacuum Science \& Technology A 2019, 37, 30902.

(32) Profijt, H. B.; Potts, S. E.; van de Sanden, M. C. M.; Kessels, W. M. M. Plasma-Assisted Atomic Layer Deposition: Basics, Opportunities, and Challenges. Journal of Vacuum Science \& Technology A: Vacuum, Surfaces, and Films 2011, 29, 50801.

(33) Lim, B. S.; Rahtu, A.; Gordon, R. G. Atomic layer deposition of transition metals. Nature materials 2003, 2, 749-754.

(34) Lee, H.-B.-R.; Kim, W.-H.; Lee, J. W.; Kim, J.-M.; Heo, K.; Hwang, I. C.; Park, Y.; Hong, S.; Kim, H. High Quality Area-Selective Atomic Layer Deposition Co Using Ammonia Gas as a Reactant. J. Electrochem. Soc. 2010, 157, D10.

(35) Klesko, J. P.; Kerrigan, M. M.; Winter, C. H. Low Temperature Thermal Atomic Layer Deposition of Cobalt Metal Films. Chem. Mater. 2016, 28, 700-703.

(36) Park, K.-H.; Bradley, A. Z.; Thompson, J. S.; Marshall, W. J. Nonfluorinated volatile copper(I) 1,3-diketiminates as precursors for Cu metal deposition via atomic layer deposition. Inorganic chemistry 2006, 45, 8480-8482.

(37) Lee, B. H.; Hwang, J. K.; Nam, J. W.; Lee, S. U.; Kim, J. T.; Koo, S.-M.; Baunemann, A.; Fischer, R. A.; Sung, M. M. Low-temperature atomic layer deposition of copper metal thin films: self-limiting surface reaction of copper dimethylamino-2-propoxide with diethylzinc. $\mathrm{An}$ gewandte Chemie (International ed. in English) 2009, 48, 4536-4539. (38) Zhong, Z.; Wang, X.; Ding, J.; Yuan, N. Nanometer-thick copper films grown by thermal atomic layer deposition. Thin Solid Films 2015, 589, 673-680.

(39) Vidjayacoumar, B.; Emslie, D. J. H.; Clendenning, S. B.; Blackwell, J. M.; Britten, J. F.; Rheingold, A. Investigation of AlMe 3 , BEt 3 , and ZnEt 2 as Co-Reagents for Low-Temperature Copper Metal ALD/PulsedCVD. Chem. Mater. 2010, 22, 4844-4853.

(40) Maimaiti, Y.; Elliott, S. D. Kinetics and Coverage Dependent Reaction Mechanisms of the Copper Atomic Layer Deposition from Copper Dimethylamino-2-propoxide and Diethylzinc. Chem. Mater. 2016, 28, 6282-6295.

(41) Emslie, D. J.; Chadha, P.; Price, J. S. Metal ALD and pulsed CVD: Fundamental reactions and links with solution chemistry. Coordination Chemistry Reviews 2013, 257, 3282-3296.
(42) Rowlette, P. C.; Allen, C. G.; Bromley, O. B.; Dubetz, A. E.; Wolden, C. A. Plasma-Enhanced Atomic Layer Deposition of Semiconductor Grade ZnO Using Dimethyl Zinc. Chem. Vap. Deposition 2009, 15 $15-20$.

(43) Muneshwar, T.; Shoute, G.; Barlage, D.; Cadien, K. Plasma enhanced atomic layer deposition of $\mathrm{ZnO}$ with diethyl zinc and oxygen plasma: Effect of precursor decomposition. Journal of Vacuum Science \& Technology A: Vacuum, Surfaces, and Films 2016, 34, 50605.

(44) Mai, L.; Mitschker, F.; Bock, C.; Niesen, A.; Ciftyurek, E.; Rogalla, D.; Mickler, J.; Erig, M.; Li, Z.; Awakowicz, P. et al. From Precursor Chemistry to Gas Sensors: Plasma-Enhanced Atomic Layer Deposition Process Engineering for Zinc Oxide Layers from a Nonpyrophoric Zinc Precursor for Gas Barrier and Sensor Applications. Small (Weinheim an der Bergstrasse, Germany) 2020, 16, e1907506.

(45) Nieminen, H.-E.; Kaipio, M.; Ritala, M. In Situ Reaction Mechanism Study on Atomic Layer Deposition of Intermetallic Co 3 Sn 2 Thin Films. Chem. Mater. 2020, 32, 8120-8128.

(46) Väyrynen, K.; Hatanpää, T.; Mattinen, M.; Mizohata, K.; Meinander, K.; Räisänen, J.; Link, J.; Stern, R.; Ritala, M.; Leskelä, M. Atomic Layer Deposition of Intermetallic Co 3 Sn 2 and Ni 3 Sn 2 Thin Films. Adv. Mater. Interfaces 2019, 6, 1801291.

(47) Langguth, E.; van Thu, N.; Shakoor, A.; Jacob, K.; Thiele, K.-H. Beiträge zur Chemie der Alkylverbindungen von Übergangsmetallen. XXXVI. Zur Existenz von 3(N, N-Dimethylamino)propyl-Verbindungen der 3d-Elemente und des Zirconiums. Z. Anorg. Allg. Chem. (Zeitschrift für anorganische und allgemeine Chemie) 1983, 505, 127-133.

(48) Liang, H.; Gordon, R. G. Atmospheric pressure chemical vapor deposition of transparent conducting films of fluorine doped zinc oxide and their application to amorphous silicon solar cells. J Mater Sci 2007, 42, 6388-6399.

(49) Zemann, J. Crystal structures, 2 nd edition. Vol. 1 by R. W. G. Wyckoff. Acta Cryst 1965, 18, 139.

(50) Spectral Database for Organic Compounds. SDBSWeb : https://sdbs.db.aist.go.jp (National Institute of Advanced Industrial Science and Technology, 10.12.2020).

(51) Xu, H.; Bernskoetter, W. H. Mechanistic considerations for C-C bond reductive coupling at a cobalt(III) center. Journal of the American Chemical Society 2011, 133, 14956-14959.

(52) Väyrynen, K.; Hatanpää, T.; Mattinen, M.; Heikkilä, M.; Mizohata, K.; Meinander, K.; Räisänen, J.; Ritala, M.; Leskelä, M. Diamine Adduct of Cobalt(II) Chloride as a Precursor for Atomic Layer Deposition of Stoichiometric Cobalt(II) Oxide and Reduction Thereof to Cobalt Metal Thin Films. Chem. Mater. 2018, 30, 3499-3507.

(53) Ritala, M.; Leskelä, M.; Rauhala, E.; Haussalo, P. Atomic Layer Epitaxy Growth of TiN Thin Films. J. Electrochem. Soc. 1995, 142, 27312737.

(54) Biesinger, M. C.; Payne, B. P.; Grosvenor, A. P.; Lau, L. W.; Gerson, A. R.; Smart, R. S. Resolving surface chemical states in XPS analysis of first row transition metals, oxides and hydroxides: $\mathrm{Cr}, \mathrm{Mn}, \mathrm{Fe}, \mathrm{Co}$ and Ni. Applied Surface Science 2011, 257, 2717-2730.

(55) Handbook of X-ray photoelectron spectroscopy: A reference book of standard spectra for identification and interpretation of XPS data;

Moulder, J. F.; Chastain, J., Eds., Update; Perkin-Elmer Corporation:

Eden Prairie, Minn., 1992.

(56) Zhang, Z.; Nallan, H. C.; Coffey, B. M.; Ngo, T. Q.; Pramanik, T.; Banerjee, S. K.; Ekerdt, J. G. Atomic layer deposition of cobalt oxide on oxide substrates and low temperature reduction to form ultrathin cobalt metal films. Journal of Vacuum Science \& Technology A 2019, 37, 10903. (57) Hantsche, H. High resolution XPS of organic polymers, the scienta ESCA300 database. By G. Beamson and D. Briggs, Wiley, Chichester 1992, 295 pp., hardcover, £ 65.00, ISBN 0-471-93592-1. Adv. Mater. 1993, 5,778 .

(58) Lange's Handbook of Chemistry, Seventeenth Edition; McGraw-Hill Professional.

(59) Andrews, P. C.; Raston, C. L.; Skelton, B. W.; White, A. H. A gem Organodizinc Species Assembled in a Tetrameric Cage. Organometallics 1998, 17, 779-782.

(60) Kresse, G.; Joubert, D. From ultrasoft pseudopotentials to the projector augmented-wave method. Phys. Rev. B 1999, 59, 1758-1775.

(61) Perdew; Chevary; Vosko; Jackson; Pederson; Singh; Fiolhais. Atoms, molecules, solids, and surfaces: Applications of the generalized gradient approximation for exchange and correlation. Physical review. B, Condensed matter 1992, 46, 6671-6687.

(62) Perdew; Burke; Ernzerhof. Generalized Gradient Approximation Made Simple. Physical review letters 1996, 77, 3865-3868. 
(63) Monkhorst, H. J.; Pack, J. D. Special points for Brillouin-zone integrations. Phys. Rev. B 1976, 13, 5188-5192.

(64) Maimaiti, Y.; Elliott, S. D. Precursor Adsorption on Copper Surfaces as the First Step during the Deposition of Copper: A Density Functional Study with van der Waals Correction. J. Phys. Chem. C 2015, 119, 93759385.

(65) Yu, M.; Trinkle, D. R. Accurate and efficient algorithm for Bader charge integration. The Journal of chemical physics 2011, 134, 64111.

(66) Tang, W.; Sanville, E.; Henkelman, G. A grid-based Bader analysis algorithm without lattice bias. Journal of physics. Condensed matter : an Institute of Physics journal 2009, 21, 84204.

(67) Mayer, M. Improved physics in SIMNRA 7. Nuclear Instruments and Methods in Physics Research Section B: Beam Interactions with Materials and Atoms 2014, 332, 176-180. 